\title{
Potyviral Gene-Silencing Suppressor HCPro Interacts with Salicylic Acid (SA)-Binding Protein 3 to Weaken SA-Mediated Defense Responses
}

\author{
Sylvain Poque, ${ }^{1}$ Hui-Wen Wu, ${ }^{2}$ Chung-Hao Huang, ${ }^{1}$ Hao-Wen Cheng, ${ }^{3}$ Wen-Chi Hu, ${ }^{3}$ Jun-Yi Yang, ${ }^{4}$ \\ David Wang, ${ }^{5}$ and Shyi-Dong Yeh ${ }^{1,2,3, \dagger}$ \\ ${ }^{1}$ Department of Plant Pathology, National Chung-Hsing University, Taichung City 40227, Taiwan, R.O.C.; ${ }^{2}$ Agricultural \\ Biotechnology Center, National Chung-Hsing University; ${ }^{3} \mathrm{NCHU}-U C D$ Plant and Food Biotechnology Center, National Chung- \\ Hsing University; ${ }^{4}$ Institute of Biochemistry, National Chung-Hsing University; and ${ }^{5}$ Department of Forestry, National Chung- \\ Hsing University
}

Accepted 1 September 2017.

\begin{abstract}
The viral infection process is a battle between host defense response and pathogen antagonizing action. Several studies have established a tight link between the viral RNA silencing suppressor (RSS) and the repression of salicylic acid (SA)-mediated defense responses, nonetheless host factors directly linking an RSS and the SA pathway remains unidentified. From yeast two-hybrid analysis, we identified an interaction between the potyviral RSS helper-component proteinase (HCPro) and SA-binding protein SABP3. Co-localization and bimolecular fluorescence complementation analyses validated the direct in vivo interaction between Turnip mosaic virus (TuMV) HCPro and the Arabidopsis homologue of SABP3, AtCA1. Additionally, transient expression of TuMV HCPro demonstrated its ability to act as a negative regulator of AtCA1. When the plants of the AtCA1 knockout mutant line were inoculated with TuMV, our results indicated that AtCA1 is essential to restrict viral spreading and accumulation, induce $\mathrm{SA}$ accumulation, and trigger the SA pathway. Unexpectedly, the AtCA1 overexpression line also displayed a similar phenotype, suggesting that the constitutive expression of AtCA1 antagonizes the SA pathway. Taken together, our results depict AtCA1 as an essential regulator of $\mathrm{SA}$ defense responses. Moreover, the interaction of potyviral HCPro with this regulator compromises the SA pathway to weaken host defense responses and facilitate viral infection.
\end{abstract}

Many plant viruses of the genus Potyvirus (family Potyviridae) cause severe damage in a wide range of economically important crops (Ivanov et al. 2014; Revers and García 2015). They have a conserved genomic organization consisting of a large open reading frame (ORF) and another shorter ORF (pretty interesting potyvirus ORF, PIPO) within the P3 coding sequence in a reading frame different from the polyprotein (Chung et al. 2008; White 2015). These two ORFs generate a large polyprotein and a transframed protein, which are processed by three virus-encoded proteases into 11 mature viral proteins, designated P1, HCPro (helper-component proteinase), P3, P3NPIPO, 6K1, CI, 6K2, NIa-VPg, NIa-Pro, NIb, and CP (coat protein)

${ }^{\dagger}$ Corresponding author: Shyi-Dong Yeh; E-mail: sdyeh@nchu.edu.tw

*The $\boldsymbol{e}$-Xtra logo stands for "electronic extra" and indicates that two supplementary figures are published online.

@ 2018 The American Phytopathological Society
(Carrington et al. 1989; García et al. 2014; Riechmann et al. 1992). Most of these proteins are multifunctional and play different roles during virus infection. This infection process has been described as an unending battle between host and pathogen, forcing plant viruses in a perpetual evolution to counteract plant defense responses, such as RNA silencing (Ruiz et al. 1998; Simón-Mateo et al. 2011) or the salicylic acid (SA)-dependent defense pathway (Malamy et al. 1990; Vlot et al. 2009; White 1979).

A perfect illustration of viral strategy to avoid plant defense responses is the well-characterized potyviral protein HCPro, which has RNA silencing suppressor (RSS) activity (Anandalakshmi et al. 1998). Most potyviruses have a second suppressor of RNA silencing, viral genome-linked protein (VPg), whose function is yet poorly characterized; nonetheless, recent study demonstrated that Turnip mosaic virus (TuMV) VPg can reduce a key component of the RNA silencing pathway (Cheng and Wang 2017). RNA silencing is a key player in the posttranscriptional regulation of physiological processes of the host, providing virus-specific defense in response to the recognition of a general elicitor, double-stranded (ds)RNA (Bouché et al. 2006; Ruiz et al. 1998; Voinnet 2001). During antiviral-based silencing, viral dsRNAs are recognized and are cleaved into viral short interfering (vsi)RNAs by Dicer-like proteins (DCLs) (Nakahara et al. 2012). These primary vsiRNAs induce host RNA-dependent RNA polymerases to generate secondary vsiRNA to amplify and maintain the antiviral silencing response. Generated vsiRNAs are loaded into specific Argonaute proteins, the effector components of the RNA-induced silencing complex, to target and cleave viral RNA sharing sequence homology with vsiRNAs (Kim et al. 2014; Morel et al. 2002; Wang et al. 2011). HCPro interferes with both micro RNA and short-interfering RNA pathways (Kasschau et al. 2003; Kung et al. 2014; Wu et al. 2010) through its ability to inhibit DCL2- and DCL4mediated post-transcriptional gene silencing (PTGS) (Kung et al. 2014; Lin et al. 2007). Moreover, HCPro silencing suppressor activity correlates with its ability to bind small RNA (del Toro et al. 2017). Most of HCPro functions are based on the central region of the protein. This central region harbors a highly conserved FRNK motif and involves genome amplification, RNA binding activity, and suppression of both PTGS and virus-induced gene silencing (Kasschau and Carrington 2001; Kung et al. 2014; Plisson et al. 2003; Wu et al. 2010). Other functions of HCPro, such as aphid transmission $(\mathrm{N}$ terminal region of HCPro), virus replication (central region of 
HCPro), and the protease activity (C-terminal region of HCPro) have also been described (Plisson et al. 2003). The central and C-terminal regions of HCPro are also responsible for cell-tocell and systemic movement of the virus (Plisson et al. 2003). Interestingly, a study demonstrates that one mutation in TuMV HCPro essential motif FRNK leads to downregulation of viral titer and correlates with the induction of innate immune responses, including SA-mediated defense responses (Kung et al. 2014). In addition, a recent study shows that HCPro of Tobacco vein banding mosaic virus is able to activate the SA pathway by interfering with DNA methylation (Yang et al. 2016). These results suggest a possible crosstalk between RSS and the SAdependent defense pathway.

The endogenous phytohormone SA plays a central role in plant defense signaling. It is required for the recognition of pathogen infection and subsequent establishment of local resistance in the infected region as well as systemic resistance at the whole-plant level (Carr et al. 2010; Malamy et al. 1990; Shah 2003; Vernooij et al. 1994). SA accumulation is induced upon infection of several pathogens (Delaney et al. 1994; Lu 2009; Métraux et al. 1990). SA is synthesized from chorismate via isochorismate. The enzymes isochorismate synthase (ICS) and isochorismate pyruvate lyase catalyze the two steps from chorismate to SA (Serino et al. 1995). Biosynthesis of SA is mostly controlled by the SA-induction deficient 2 (SID2) gene, which encodes a putative chloroplast-localized ICS (Wildermuth et al. 2001). Several plant factors were identified as regulators involved in the SA-mediated defense pathway. The activation of the SA pathway requires a coordinated interplay between enhanced disease susceptibility 1 (EDS1) and phytoalexin deficient 4 (PAD4), this interaction directly contributing to a positive loop of SA accumulation (Rietz et al. 2011; Wiermer et al. 2005). Beyond EDS1 and PAD4, numerous SA-positive regulators have been identified, including ACD6 ( $\mathrm{Lu}$ et al. 2003), EDS5 (Nawrath et al. 2002), ALD1 (Song et al. 2004), WIN3 (HOP 1-1-interacting 3) (Lee et al. 2007), and MOS (Palma et al. 2005). Another key regulator of SA signaling is the regulatory protein NPR1. Optimal levels of SA allow changes in the cellular redox homeostasis, initiating the reduction of the NPR1 oligomer (Mou et al. 2003), then, SA would directly interact with NPR1 to cause the final disassembly of the oligomer (Wu et al. 2012). NPR1 monomer enters the nucleus to interact with TGA and WRKY transcription factors (Dong et al. 2003; Loake and Grant 2007; Pieterse and Van Loon 2004), leading to transcriptional upregulation of the SA-dependent pathogenesis-related (PR) proteins (Durrant and Dong 2004). The accumulation of SA is required for inducing defense response upon pathogen infection in inoculated leaves and generate one or more multiple mobile signals triggering systemic acquired resistance (SAR), a broad spectrum and long-lasting immune response (Shah and Zeier 2013; Vlot et al. 2008, 2009).

To clarify the role of SA in defense signaling, several SAbinding proteins (SABPs) in tobacco have been identified. The first characterized SABP possesses a catalase activity, allowing the degradation of $\mathrm{H}_{2} \mathrm{O}_{2}$. Its activity is specifically inhibited by $\mathrm{SA}$, leading to an accumulation of reactive oxygen species, which is related to SA-induced cell death (Chen et al. 1993). The second identified SABP2 has methyl salicylate (MeSA) esterase activity, catalyzing the hydrolysis of MeSA to SA. This enzyme is required for the activation of SAR (Forouhar et al. 2005; Kumar et al. 2006; Park et al. 2007). It has been suggested that during the activation of SAR, MeSA accumulates and, then, moves from infected leaves to distal leaves. In the distal leaves, SABP2 hydrolyzed MeSA to produce SA, activating $\mathrm{SA}$-mediateddefense responses in the pathogen-free organs (Dempsey and Klessig 2012). The third SABP, SABP3, is tobacco chloroplastic carbonic anhydrase (CA), which is required for the induction of the Pto:avrPto-mediated hypersensitive response formation in Nicotiana benthamiana (Slaymaker et al. 2002). Furthermore, in A. thaliana, the chloroplastic CA1 (AtCA1 or AtSABP3) binding activity to SA as well as its CA activity are essential for the induction of host resistance during pathogen infection (Wang et al. 2009). Altogether, these SABPs appear to be essential for the regulation of the SA-dependent defense pathway.

Our preliminary results, obtained by screening a Chenopodium quinoa (Willd.) library by yeast two-hybrid (Y2H) assay, using Zucchini yellow mosaic virus (ZYMV) HCPro as a bait, leads to the identification of a strong interaction between the potyviral RSS HCPro and a putative $C$. quinoa CA (CqCA1). This newly identified protein shows high identity with the SABP AtCA1, indicating a possible implication of HCPro in the modulation of SA-mediated defense response. Unlike C. quinoa, Arapbidosis thaliana (L.) Heynh. is commonly used as an ideal model plant for the acquisition of knowledge on basic plant biology and on adaptation to biotic or abiotic stress. Moreover, A. thaliana is susceptible to various viral pathogens, making it an ideal host for the characterization of plant-virus interactions. Among potyviruses, TuMV has the ability to infect wild Brassicaceae species as their natural habitats (Pallett et al. 2002; Thurston et al. 2001), this makes the virus a perfect partner to investigate innate defense response.

In this study, we used TuMV as a model virus to investigate the implication of HCPro and AtCA1 on the SA-dependent defense pathway in A. thaliana. We verified the relevance of the TuMV HCPro interaction with AtCA1. Our results demonstrated that HCPro acts as a negative regulator of AtCA1. Using a knockout mutant line, our results indicated AtCA1 is essential to restrict virus spread and accumulation, induce SA accumulation, and trigger the SA pathway. Surprisingly, similar results were observed when AtCA1 was overexpressed, suggesting a possible negative regulation of the SA-dependent defense pathway. Furthermore, we have verified the ability of HCPro to negatively impact the SA pathway, suggesting its critical role in the modulation of innate defense responses.

\section{RESULTS}

\section{TuMV HCPro interacts}

with CqCA1 and its $A$. thaliana homologue AtCA1.

In the scope of identifying new host factors interacting with HCPro, a screening of the C. quinoa-expressing library using ZYMV HCPro (ZHC) as bait was conducted by $\mathrm{Y} 2 \mathrm{H}$ analysis. The $C$. quinoa library was constructed in fusion with the GAL4 activation domain (pGBK vector), while $\mathrm{ZHC}$ was fused with the GAL4 binding domain (pGAD vector). Given that HCPro has a self-interacting capability (Lin et al. 2009; UrcuquiInchima et al. 1999; Zheng et al. 2011), the combination of pGBK-ZHC and pGAD-ZHC was used as a positive control (Fig. 1A). Among several positive interactions, one sample homologue of Nicotiana tabacum SABP, NtSABP3, mentioned as the $C$. quinoa SABP3 gene (CqSABP3) (Jarvis et al. 2017), revealed a strong interaction with ZHC (Fig. 1A) on selective media lacking tryptophan (Trp), leucine (Leu), histidine (His), and adenine. This protein showed high homology with both NtSABP3 and AtCA1 (Fig 1B), including the presence of a conserved cysteine at position 280, corresponding to the Cys280 essential for AtCA1 enzyme activity (Wang et al. 2009). Altogether, this allowed us to identify one HCPro-interacting protein as a CA1, this newly identified host-factor was referred as a putative CqCA1 hereafter.

To confirm that both ZHC and TuMV HCPro (TuHC) can directly interact with AtCA1, ZHC, TuHC, and full-length 
cDNA of $\beta$-glucuronidase (GUS) were cloned into pMAL-DCmyc vector to generate recombinant proteins $\mathrm{ZHC}-$ myc, TuHCmyc, and GUS-myc, respectively, while AtCA1 was cloned into pMAL-DC-HA (hemagglutinin) vector to generate the recombinant protein AtCA1-HA. Monoclonal antibody (MAb) against myc-tag was used to pull down the coimmunoprecipitation (CoIP) of AtCA1-HA with either ZHC-myc, TuHC-myc, or GUSmyc, while polyclonal antibodies (PAb) against HA-tag were used for revelation. The negative control of the Co-IP of AtCA1HA and GUS-myc showed a barely detectable signal, while the Co-IP of AtCA1-HA with both ZHC-myc and TuHC-myc revealed strong signals (Supplementary Fig. S1). The observed signal in the negative control could be explained by some unspecific interaction; on the other hand, the strong intensity of the signal detected in AtCA1-HA and ZHC-myc or TuHC-myc CoIP displays a clear specific interaction. This result indicated that both ZYMV and TuMV HCPros interact with AtCA1 protein under in vitro conditions.

Since the HCPro-CA1 interaction was established using the ZYMV-C. quinoa pathosystem, we first evaluated cellular localization of potyviral HCPro and AtCA1. ZHC and TuHC were fused with yellow fluorescent protein (ZHC-YFP and TuHC-YFP, respectively); meanwhile AtCA1 was fused with cyan fluorescent protein (AtCA1-CFP), and protein localization was monitored by fluorescent microscopy. Transient expression in $N$. benthamiana plants with AtCA1-CFP coexpressing with either ZHC-YFP or TuHC-YFP showed that AtCA1 as well as both HCPros were localized in the cytoplasm (Fig. 2, left and central panels). Likewise, individual expressions of AtCA1-CFP, ZHC-YFP, and TuHC-YFP showed the same localization (data not shown). AtCA1 cytoplasmic localization might be explained by the fact that chloroplastic AtCA1 is produced in the nucleus and is then targeted to the chloroplast, through a chloroplastic transit peptide (Fett and Coleman 1994). The merged image (Fig. 2, right panel) revealed a clear colocalization between AtCA1CFP and each of ZHC-YFP and TuHC-YFP, displaying that, despite the chloroplastic function of AtCA1, both ZYMV and TuMV HCPros colocalize with the A. thaliana homologue of CqCA1, i.e., AtCA1.

Therefore, to validate this link in the A. thaliana-TuMV pathosystem, we further conducted a bimolecular fluorescence complementation (BiFC) assay to test the direct interaction between TuHC and AtCA1. The N-terminal fragment of YFP was fused to the $\mathrm{N}$ termini of TuHC and AtCA1 to generate $\mathrm{YFP}^{\mathrm{N}}$ TuHC and $\mathrm{YFP}^{\mathrm{N}}$-AtCA1, while the C-terminal fragment of YFP was fused to the $\mathrm{N}$ termini of TuHC and TuMV CP (TuCP) to generate YFP $^{\mathrm{C}}$-TuHC and $\mathrm{YFP}^{\mathrm{C}}$-TuCP. Plants were infiltrated with each construct with pairwise combinations. No fluorescence was detected in the single infiltration (data not shown). Since HCPro was reported to self-interact, coinfiltration of $\mathrm{YFP}^{\mathrm{N}}$-TuHC and $\mathrm{YFP}^{\mathrm{C}}$-TuHC was used as a positive control. We were able to detect YFP fluorescence for the positive control as well as the YFP $^{\mathrm{N}}$-AtCA1 and YFP Y $^{\mathrm{C}} \mathrm{TuHC}$ combination (Fig. 3). As another negative control, no YFP signal was observed when $\mathrm{YFP}^{\mathrm{N}}$-AtCA1 was coinfiltrated with the $\mathrm{CP}$ of TuMV (YFP ${ }^{\mathrm{C}}$-TuCP) (Fig. 3). Our BiFC results demonstrated
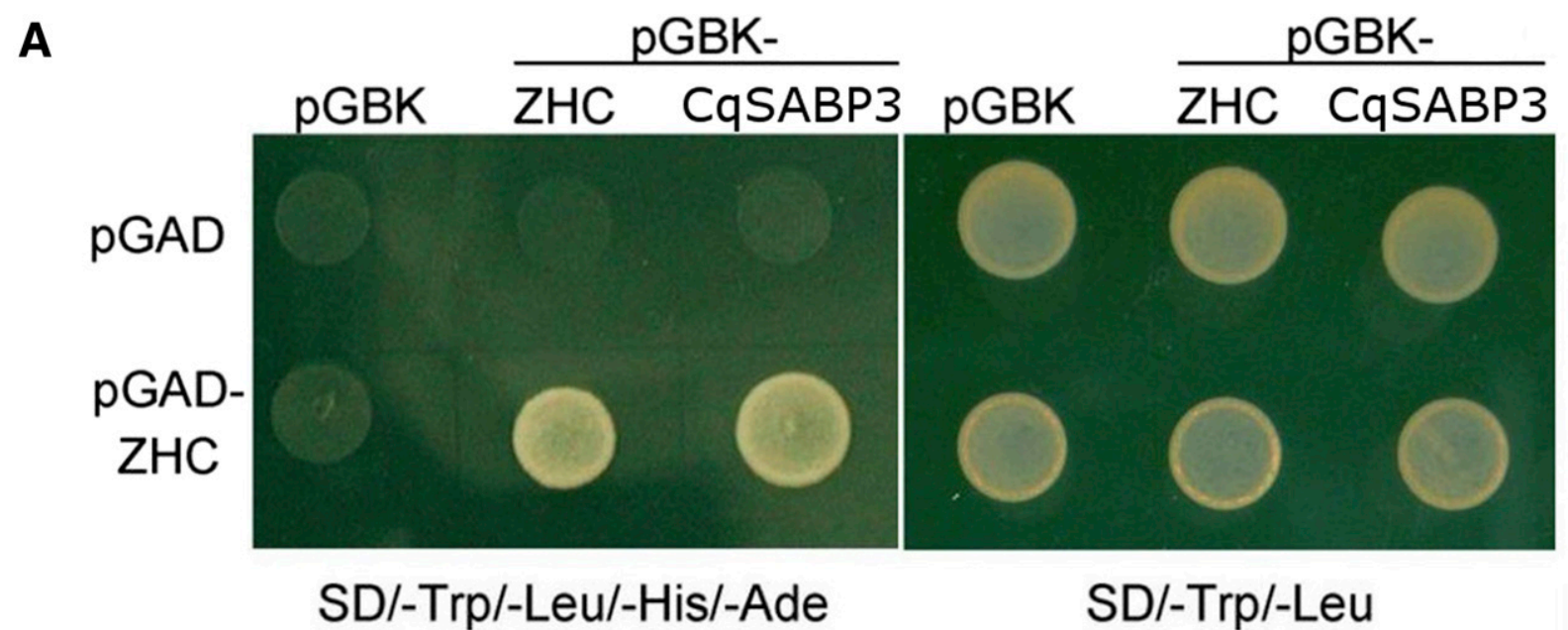

\section{SD/-Trp/-Leu/-His/-Ade SD/-Trp/-Leu}

B

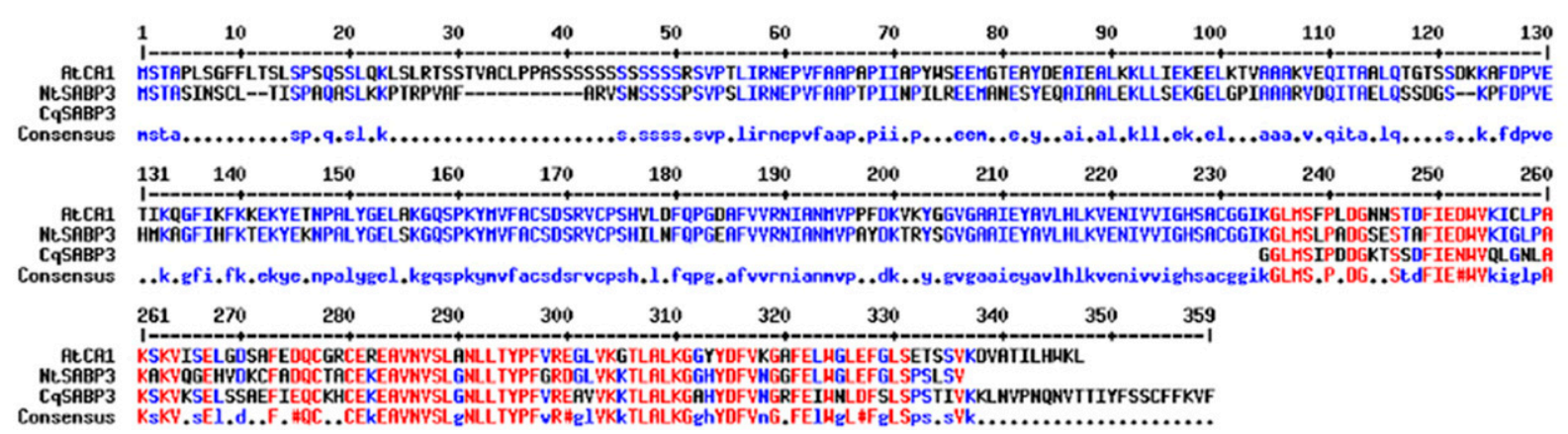

Fig. 1. Identification of Chenopodium quinoa putative carbonic anhydrase by yeast two-hybrid analysis. A, Analysis of CqSABP3 direct interaction with Zucchini yellow mosaic virus HCPro by yeast two-hybrid. Each cotransformed yeast cell was grown on synthetic defined (SD) medium lacking tryptophan (Trp), leucine (Leu), histidine (His), and adenine (Ade). pGAD vector contained the GAL4 activation domain and pGBK vector contained the GAL4 binding domain. B, Amino acid alignment of Arabidopsis thaliana carbonic anhydrase (AtCA1), Nicotiana tabacum salicylic acid-binding protein 3 (NtSABP3), and partial amino acid sequence of the putative C. quinoa SABP3 gene (CqSABP3). 
the specificity of interaction between AtCA1 and TuMV HCPro.

HCPro acts as a negative regulator of AtCA1.

We generated two A. thaliana mutant lines, an AtCAl knockout line (namely, cal) obtained by screening homozygous progeny of the Salk_106570, T-DNA insertion line, (Arabidopsis Biological Resource Center [ABRC], Ohio State University, Columbus, OH, U.S.A.) and an AtCAl overexpression line (namely, CA1-OE) obtained in our laboratory by floral-dip transformation (Clough and Bent 1998; Zhang et al. 2006) of the A. thaliana wild-type Col-0. AtCA1 protein accumulation was assessed in untreated 4-week-old plants, with anti-CA1 polyclonal antibodies, prepared in our laboratory by rabbit immunization with the purified bacteria-expressed AtCA1 protein. We failed to detect AtCA1 protein in the knockout cal line, while its accumulation was increased up to $61 \%$ in the CA1-OE line as compared with the wild-type Col-0 (Fig. 4A). These results validated these mutant lines.

To determine whether HCPro protein would affect AtCA1 expression, an Agrobacterium infiltration system was employed to transiently express TuMV HCPro protein. In this system, Agrobacterium strain carrying either HCPro fused with fulllength YFP (HC-YFP) at the $\mathrm{C}$ terminus or $\mathrm{YFP}^{\mathrm{C}}$-TuCP were infiltrated in leaves of Col-0, cal, and CA1-OE plants. The construct expressing $\mathrm{YFP}^{\mathrm{C}}$-TuCP was used as a control. Two days postinfiltration, the expression of AtCAl transcript was measured by quantitative reverse transcription-polymerase chain reaction (qRT-PCR), AtCAl expression in the control condition (YFP ${ }^{\mathrm{C}}$-TuCP) was completely impaired in cal and was significantly upregulated in CA1-OE as compared with Col-0 (Fig. 4B), consistent with the protein accumulation analysis of mutant lines. When HCPro was transiently expressed, AtCA1 transcript was reduced by 72 and $45 \%$ in Col- 0 and CA1-OE, respectively, compared with the control expressing TuMV CP (Fig. 4B). Furthermore, Western blot analysis showed that transient expression of HCPro in the CA1-OE background leads to a $52 \%$ reduction of AtCA1 protein accumulation (Fig. 4C). Similarly, in Col-0, we observed a $26 \%$ decrease of AtCA1 when HCPro was transiently expressed, as compared with CP (Fig. 4C). These results revealed that TuMV HCPro protein has the ability to specifically reduce AtCA1 transcript and protein accumulation, suggesting that HCPro acts as a negative regulator of AtCA1.

\section{TuMV accumulation is enhanced}

in AtCA1 knockout and overexpression lines.

Since TuMV HCPro negatively regulates AtCA1, we decided to look into the function of AtCA1 during virus infection. For this purpose, TuMV accumulation in inoculated leaves was assessed by challenging Col-0, cal, and CA1-OE lines with a TuMV infectious clone expressing the YFP (TuMV-YFP). At 2 days postinoculation (dpi), initial infection spots caused by the virus were monitored by fluorescent microscopy.

Fluorescence microscopy of cal inoculated leaves revealed wider initial infection spots as compared with those in Col0 plants (Fig. 5A). Average size of these loci was estimated using ImageJ software (Slaymaker et al. 2002); analysis of four independent experiments confirmed that initial virus spread on infected leaves was four times higher in cal compared with that on Col-0 (Fig. 5B). This means an absence of AtCA1 leads to acceleration of the spreading of initial infection spots, suggesting its important role in TuMV restriction at the early stage of the viral infection. In addition, AtCA1 has been reported as SABP3 (Slaymaker et al. 2002; Wang et al. 2009), implying possible involvement of AtCA1 during SA-mediated defense responses.

Surprisingly, fluorescence microscopy of CA1-OE inoculated leaves also showed increments of virus spread and accumulation (Fig. 5A). Size estimation of infection foci confirmed this observation by showing a fivefold increase of initial infection spots in CA1-OE as compared with Col-0 (Fig. 5B). This result suggested that, similar to the knockout line, AtCA1 overexpression also negatively affects plant defense responses.

\section{AtCA1 is essential to the SA induction during TuMV infection.}

To confirm that the phenotypes observed in cal and CA1-OE lines are linked to SA-mediated resistance, total SA accumulation was estimated directly, using high-performance liquid chromatography-mass spectrometry (HPLC-MS) at 2 dpi. For
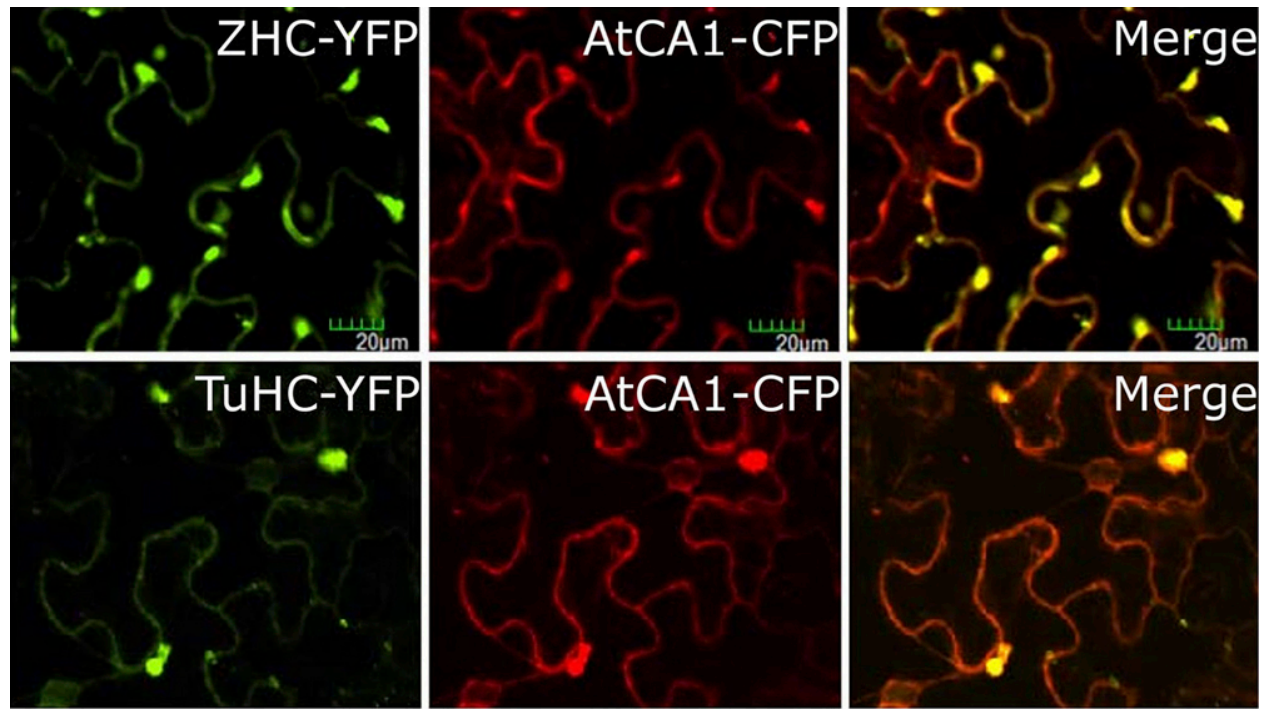

Fig. 2. Spatial colocalization of Zucchini yellow mosaic virus (ZYMV) or Turnip mosaic virus (TuMV) HCPro with Arabidopsis thaliana carbonic anhydrase (AtCA1). Transient coexpression of cyan fluorescent protein-tagged AtCA1 protein (AtCA1-CFP) with yellow fluorescent protein-tagged HCPro protein of ZYMV (ZHC-YFP) (upper panel) or YFP-tagged HCPro protein of TuMV (TuHC-YFP) (lower panel) in Nicotiana benthamiana leaves. Fluorescent microscopy shows ZHC-YFP and TuHC-YFP in green, AtCA1-CFP in red and the merge combination indicates the cytoplasmic colocalization in yellow. The results are representatives of three independent experiments. Scale bar $=20 \mu \mathrm{m}$. 
each line, total SA was extracted from a pool of treated and untreated rosette leaves of two plants either challenged with TuMV or treated with inoculation buffer (Mock).

As observed in Figure 6, SA levels in Col-0 remained low in the absence of TuMV infection while cal and CA1-OE lines showed a slight increase of SA accumulation, compared with Col-0. Following TuMV inoculation, SA levels increased drastically in Col-0. On the contrary, in cal and CA1-OE lines, TuMV failed to induce SA while CA1-OE displayed a decrease in its SA level (Fig. 6).

This failure of SA induction coupled with TuMV susceptibility enhancement in both AtCA1 knockout and overexpression lines demonstrated that the absence of AtCA1 impairs SA accumulation, resulting in a failure of SA-mediated resistance activation and facilitating the spread of TuMV. Moreover, in the TuMV-infected CA1-OE line, SA accumulation was impaired and dropped to levels lower than in the mock condition, suggesting the activation of a possible negative feedback loop, leading to an outcome similar to that of the AtCA1 knockout line, an inactivation of the SA-mediated defense pathway.

\section{AtCA1 is a key regulator of the SA pathway} during TuMV infection.

We decided to look at AtCA1 influence on the SA pathway during TuMV infection. The relative transcript accumulations of two positive regulators of SA as well as two genes induced by SA were compared in the wild type, cal, and CA1-OE lines. We first validated $A t C A 1$ accumulation and found that, in CA1$\mathrm{OE}$, accumulation was higher than in the wild type and was constant in both inoculated and mock conditions. As expected, we failed to detect $A t C A 1$ in $c a l$. Regarding Col-0, we noticed that $A t C A 1$ accumulation was modulated by TuMV and its transcript increased during the first 4 days of infection, followed by a sharp downregulation thereafter (Fig. 7A). When virus accumulation was measured by transcript accumulation of TuMV CP and HCPro, viral RNA followed the same accumulation pattern (data not shown). Our time course experiment showed higher TuMV accumulation in both the knockout $c a l$ line and the overexpression CA1-OE line as compared with the wild type and, once again, CA1-OE appeared to be more susceptible than cal (Fig. 7B). These results are consistent with our virus-spread experiment, indicating the importance of AtCA1 in TuMV restriction.

As positive regulators of SA formation, we chose to evaluate the SID2 gene involved in SA biosynthesis (Lu 2009; Wildermuth et al. 2001) and the WIN3 gene involved in SA accumulation (Lee et al. 2007; Lu 2009). In control Col-0, both positive regulators were induced at the beginning of TuMV infection. On the contrary, in the cal line, none of these positive regulators were expressed and, in CA1-OE, SID2 was not expressed while WIN3 has a lower level of expression than in Col-0 (Fig. 7C and D).
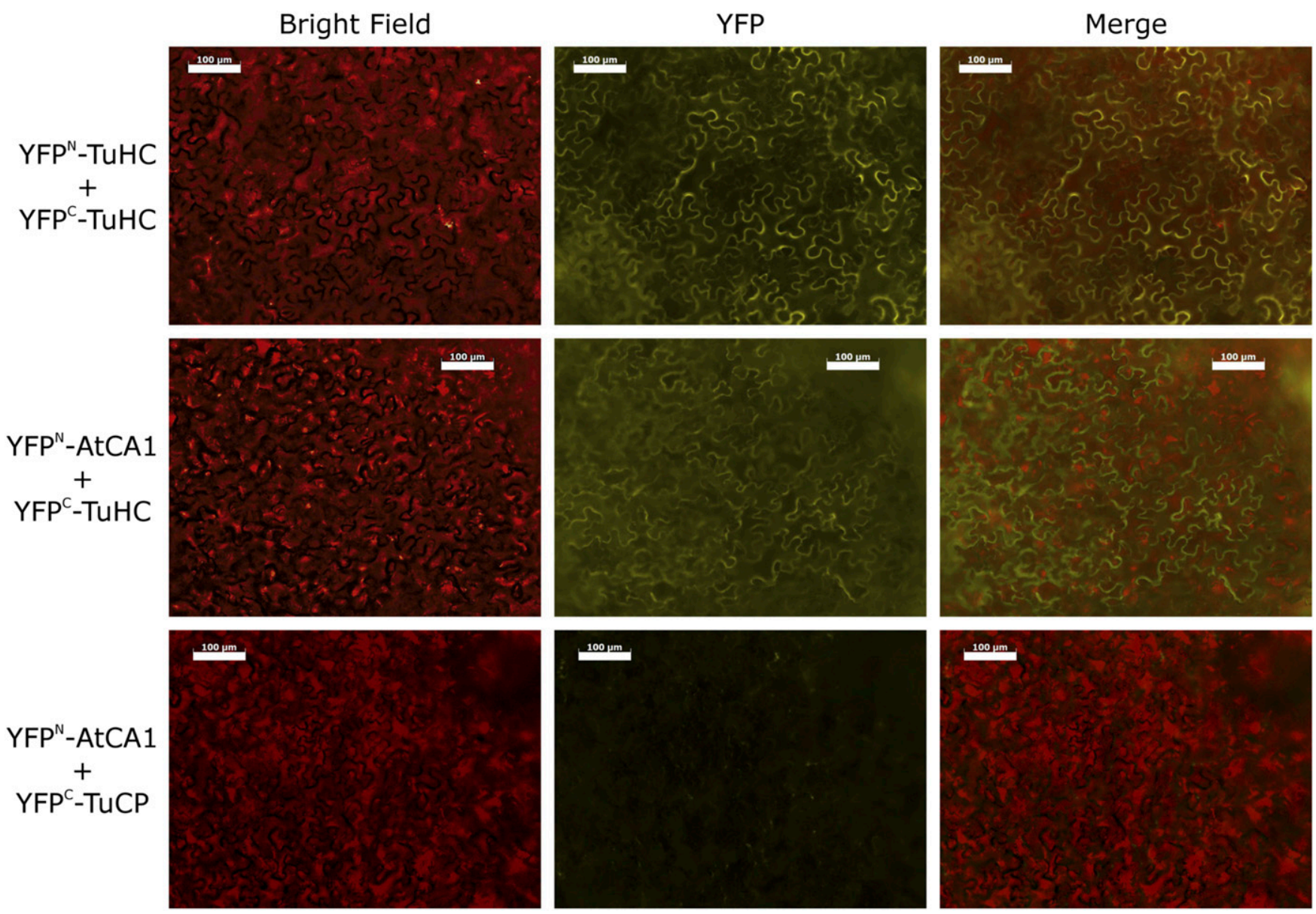

Fig. 3. Bimolecular fluorescence assay of the interaction between Arabidopsis thaliana carbonic anhydrase (AtCA1) and Turnip mosaic virus (TuMV) HCPro (TuHC) or TuMV coat protein (TuCP). Proteins were transiently expressed in Nicotiana benthamiana leaves by agroinfiltration. Positive control YFP ${ }^{\mathrm{N}}$ TuHC/YFP ${ }^{\mathrm{C}}$-TuHC (upper panel), negative control $\mathrm{YFP}^{\mathrm{N}}$-AtCA1/YFP ${ }^{\mathrm{C}}$-TuCP (lower panel), and tested interaction YFP ${ }^{\mathrm{N}}$-AtCA1/YFP ${ }^{\mathrm{C}}$-TuHC (middle panel) are shown. Bright field displays chlorophyll autofluorescence, signal in the YFP column indicates the successful reconstitution of the chromophore and the merge displays the combination of both bright field and YFP (yellow fluorescent protein). The results are representatives of four independent experiments. Scale bar $=100 \mu \mathrm{m}$ 
In plants, SA-mediated resistance correlates with the presence of PR proteins (Yalpani et al. 1991). Therefore, we used PR1 and PR5 to evaluate the SA pathway response to TuMV infection. In Col-0, their expression increased over time, and, while CA1OE had very high levels of PR1 and PR5 at 2 dpi, expression decreased rapidly thereafter. In the case of $c a l$, we failed to detect any expression of both PR1 and PR5 (Fig. 7E and F).

Altogether, our results showed that, in wild type, AtCAl expression increased at the beginning of the infection at the same time positive regulators of SA were activated, and then, in the late stage of infection, AtCAI expression decreased while $P R$ gene expression increased. In the absence of $A t C A 1$, neither positive regulators nor $P R$ genes were activated, demonstrating a failure in SA-pathway induction, leading to an enhancement of TuMV susceptibility. In the presence of an abnormal proportion of AtCA1, the two positive regulators, SID2 and WIN3, of SA were drastically reduced compared with those of the wild type. $P R$ genes appeared to be strongly activated at the beginning
A

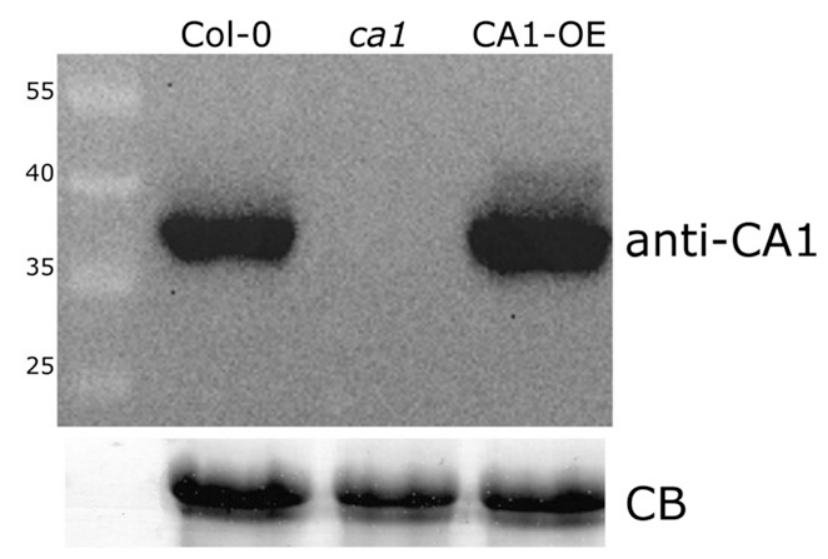

B

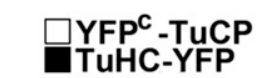

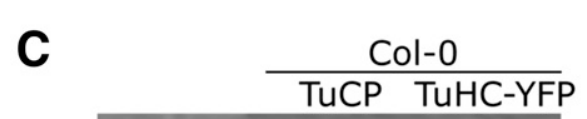
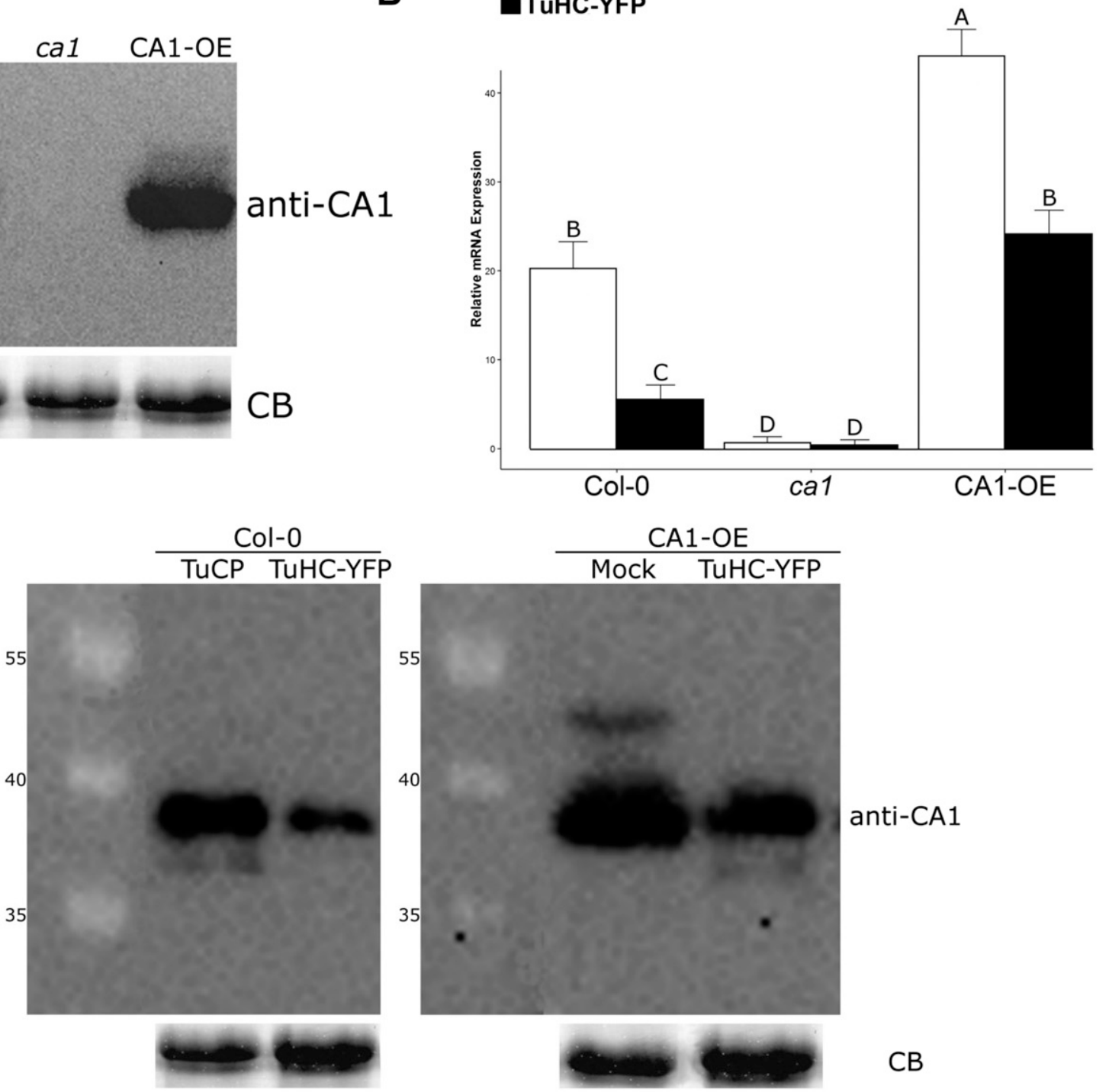

anti-CA1
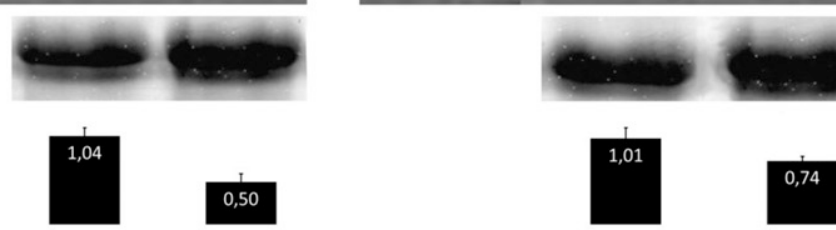

\section{Relative \\ Band \\ Intensity}

Fig. 4. Protein accumulation and relative expression levels of Arabidopsis thaliana carbonic anhydrase (AtCA1) in wild-type, AtCA1 knockout, or overexpression lines. A, Upper panel shows the Western blot analysis of seedling extracts of wild type (Col-0), AtCA1 knockout (cal), or overexpression (CA1-OE) lines of A. thaliana, using polyclonal antibodies targeting AtCA1 (anti-CA1). The results are representative of three independent experiments. B, Turnip mosaic virus (TuMV) HCPro and TuMV coat protein (CP) were transiently expressed in wild-type (Col-0), AtCA1 knockout (cal-ko), and overexpression (CA1-OE) seedlings. Two days after infiltration, total RNA was extracted and quantitative reverse transcription-polymerase chain reaction was performed. Relative expression of AtCA1 was evaluated, using A. thaliana Actin-8 for normalization. All values are the mean ( \pm standard deviation) of 12 plants taken from four separate experiments. Different letters above each sample represent statistical significance at $P<0.001$, assessed by student's $t$ test. C, TuMV HCPro and TuMV CP were transiently expressed in seedlings of the wild-type (Col-0) or overexpression (CA1-OE) lines and total protein extracts were obtained 2 days after infiltration. Upper panel shows the Western blot analysis of CA1-OE infiltrated with agroinfiltration buffer (Mock) or TuMV HCPro (TuHC-YFP) and Col-0 infiltrated with TuMV CP (TuCP) or TuMV HCPro (TuHC-YFP). Polyclonal antibodies targeting A. thaliana CA1 (anti-CA1) were used. Histograms show the intensity of Western blot immunostaining of TuHC-YFP-infiltrated CA1-OE and Col-0 leaves relative to the band intensity of their respective controls. The results are representatives of three independent experiments. The lower panels in A and C show similar loading of each lane stained with Coomassie brillant blue R250, the protein band corresponding to the RuBisCO large subunit (CB) was used as a loading control. 
of infection and then decreased after $4 \mathrm{dpi}$, displaying a completely inverted pattern compared with the wild type.

\section{TuMV HCPro acts as a negative regulator} of the SA pathway.

Our previous experiments showed that HCPro acts as a negative regulator of AtCA1, which appeared to be essential to induce SA-mediated defense responses. To prove that HCPro could impact the SA pathway, we induced this pathway by treating A. thaliana plants with a $2-\mathrm{mM}$ solution of SA. Two days later, the same plants were agroinfiltrated to transiently express either HCPro or TuMV CP, in which the latter was used as a control condition. Activation of SA-mediated defense responses was monitored the next day by measuring PR5 gene expression. As a negative control, we used a NahG mutant line that constitutively expresses the Pseudomonas putida $N a h G$ gene that encodes salicylate hydroxylase, an enzyme that converts SA to catechol (Yamamoto et al. 1965), thus resulting in reduction of SA levels and inactivation of the SA pathway in this plant (Delaney et al. 1994). As expected, neither HCPro nor CP was able to induce $P R 5$ expression in NahG plants (Fig. 8). The wildtype and overexpression CA1-OE lines showed a high level of PR5 under the control condition, resulting from SA-mediated defense response activated by SA treatment (Fig. 8). Transient expression of HCPro leads to a reduction by 63 and $47 \%$ of PR5 gene expression in Col-0 and CA1-OE, respectively (Fig. 8), demonstrating the ability of TuMV HCPro to negatively impact the SA-mediated defense response. Moreover, we noticed that SA treatment slightly activated PR5 in the knockout mutant line and ectopic expression of HCPro failed to reduce $P R 5$ gene expression. This means that, in the absence of AtCA1, HCPro failed to downregulate SA-mediated defense responses, indicating the essential role of AtCA1 for HCPro to modulate the SA pathway.

\section{DISCUSSION}

To counteract host defense responses, plant viruses develop strategies of RNA silencing suppression and inhibition of SAmediated defense responses. A recent study demonstrated that one mutation in TuMV HCPro leads to a variation of SAmediated defense responses (Kung et al. 2014). Furthermore, a study of diverse plant viruses showed that Cucumber mosaic virus (CMV, genus Cucumovirus) viral protein $\mathrm{Cmv} 2 \mathrm{~b}$, which has silencing suppressor activity by inhibiting DCL2- and DCL4mediated PTGS (Ziebell et al. 2007), also has an antagonistic
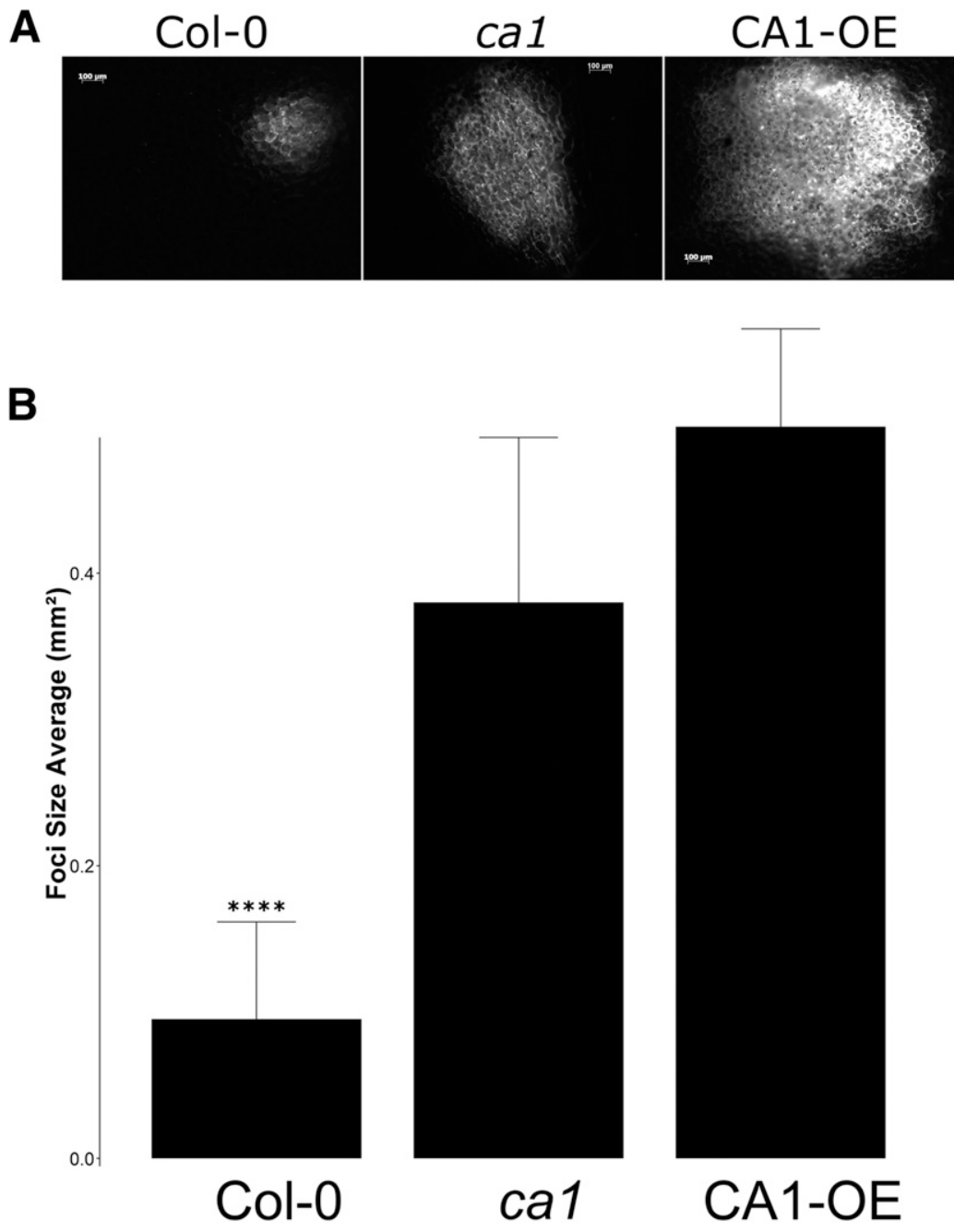

Fig. 5. Visualization and average size of initial infectious spots induced by Turnip mosaic virus (TuMV) on wild-type, Arabidopsis thaliana carbonic anhydrase (AtCA1) knockout, and overexpression lines. Wild-type (Col-0), AtCA1 knockout (ca1), and overexpression (CA1-OE) seedlings of Arabidopsis thaliana were challenged with yellow fluorescent protein (YFP)-tagged TuMV (TuMV-YFP). A, Two days postinoculation, initial infectious spots localized on the adaxial surface were monitored by fluorescent microscopy and B, their surfaces were estimated. Results displayed in A are representative of four independent experiments (scale bar $=100 \mu \mathrm{m})$, while, in B, all values are the mean ( \pm standard deviation) of 20 plants taken from four separate experiments. Asterisks $(* * * *)$ indicate $P<0.0001$. 
effect on the SA-mediated virus resistance mechanism ( $\mathrm{Ji}$ and Ding 2001). And the RSS P6 of Cauliflower mosaic virus (CaMV, genus Caulimovirus) strongly inhibited SA-dependent responses, including the expression of representative $P R$ genes, hypersensitive cell death, and basal defense against biotrophic bacterial pathogens (Love et al. 2007, 2012). Altogether, these studies clearly indicated the existence of a tight link between RSS and the repression of SA-mediated defense responses. To date, possible host factors directly linking HCPro and SA pathway have not identified yet. Here, we report for the first time the interaction of the potyviral RSS HCPro with a chloroplastic CA (AtCA1), which has been described as SABP3 (Slaymaker et al. 2002; Wang et al. 2009). Furthermore, our results revealed that this interaction leads to a weakened SA pathway during viral infection, suggesting a novel way for HCPro to modulate innate immunity.

Several data pointed out a key function of SABP3 and its homologs in disease resistance. A potato homolog of this gene was found to be quickly suppressed during the development of late blight disease, and silencing of SABP3 in N. benthamiana resulted in increased pathogen growth (Restrepo et al. 2005). Also, both $N$. benthamiana and A. thaliana SABP3 has been shown to be essential to induce a full defense response against bacterial strain (Slaymaker et al. 2002; Wang et al. 2009). It is worth noting that several studies have found chloroplastic proteins interacting with viral proteins (Cheng et al. 2013b; Feki et al. 2005; Huh et al. 2011; Jiménez et al. 2006). In addition, chloroplastic regulators guanosine tetraphosphate and pentaphospahte [(p)ppGpp] were recently found to directly regulate SA accumulation and increase TuMV susceptibility (Abdelkefi et al. 2017). Finally, multiple diverse viruses have been observed to alter chloroplast structure, size, or number (Zhao et al. 2016). In accordance with the chloroplastic localization of AtCA1, our results demonstrated that ectopic expression of TuMV HCPro in A. thaliana leads to the downregulation of both its transcript and protein accumulation, depicting HCPro as a negative regulator of SABP3.

To evaluate the effect of AtCA1 on viral spreading and accumulation, an A. thaliana mutant line lacking AtCAl was challenged with TuMV. We observed that virus spread was enhanced at 2 dpi in inoculated leaves. Furthermore, we noticed that viral accumulation was significantly increased in systemic tissue as compared with the wild type at 6 dpi. Our results indicated that AtCA1 is indispensable to restrict viral spreading, confirming its essential role in the induction of host defense responses. Nevertheless, underlying mechanisms responsible for viral spread enhancement in our study need to be further investigated. Infection efficiency could be controlled by two major factors, replication and movement; thus, to fully understand the observed phenotype, it is essential to study TuMV replication in cal and CA1-OE protoplasts in order to distinguish between the two possibilities.

The principal role of $\mathrm{CA}$ is to catalyze the reversible hydration of $\mathrm{CO}_{2}$ into bicarbonate $\left(\mathrm{HCO}_{3}{ }^{-}\right)$. In $\mathrm{C}_{3}$ plants, $\mathrm{CA}$ is distributed primarily in the stroma of chloroplasts, speculated to facilitate the supply of $\mathrm{CO}_{2}$ to ribulose-1,5-bisphosphate carboxylase/oxygenase ( $\mathrm{RuBisCO})$ by maintaining the equilibrium between $\mathrm{HCO}_{3}{ }^{-}$and $\mathrm{CO}_{2}$ within the chloroplast (Williams et al. 1996). The $\mathrm{CO}_{2}$ transformation into $\mathrm{HCO}_{3}{ }^{-}$mediated by $\mathrm{CA}$ is essential to retain inorganic carbon for the primary carboxylation reactions. For example, in multiple plant species, plastidial CA function is required for lipid biosynthesis, possibly by its interaction with acetyl-CoA carboxylase and the enzymes of the fatty acid synthase complex, to process carbon into fatty acid (FA) (Hoang and Chapman 2002). Since, AtCA1 should have the same role and FA-derived signaling has been recognized as one of the most important regulators of defense pathways (Chandra-Shekara et al. 2007; Weber 2002; Yaeno et al. 2004), we propose that AtCA1 downregulation mediated by HCPro might directly impact plant defense responses and, thus, increase host susceptibility.

FA biosynthesis affects SA pathway regulation (Falk et al. 1999; Jirage et al. 1999; Kachroo et al. 2003, 2005); this, coupled with the SA-binding property of AtCA1, led us to evaluate its possible implication on the induction of the SA pathway during TuMV infection. We demonstrated that the pathogen-dependent induction of SA was compromised in the cal line. In this mutant line, we noticed that gene expression of SID2 and WIN3, two positive regulators of SA accumulation, was completely aborted and, also, that $P R I$ and $P R 5$, the hallmark of the SA pathway induction, failed to be activated during TuMV infection. Our result revealed that, in the absence of AtCA1, SA pathway activation was completely impaired, depicting its implication in the induction of the SA pathway during viral infection. Hence, a likely hypothesis is that the decrease of AtCA1 during viral infection compromises the SA pathway, possibly through its modulation of FA biosynthesis, and weakens SA-mediated defense responses in order to facilitate viral infection.

Surprisingly, our results showed that, similarly to $c a 1$, AtCA1 overexpression also enhances TuMV spreading and accumulation. In the CA1-OE line, we observed that, 2 days after TuMV infection, the expression of $P R 1$ and $P R 2$ gene was abnormally high and their levels decreased rapidly and was almost abolished at 4 dpi. Additionally, the quantification of total SA at 3 dpi revealed that SA accumulation was not only impaired but reduced as compared with the mock condition. Altogether, these results suggest that, after viral infection, AtCA1 overexpression has an adverse effect on SA production.

Since SA plays an important role in plant growth and development (Rivas-San Vicente and Plasencia 2011), its regulation

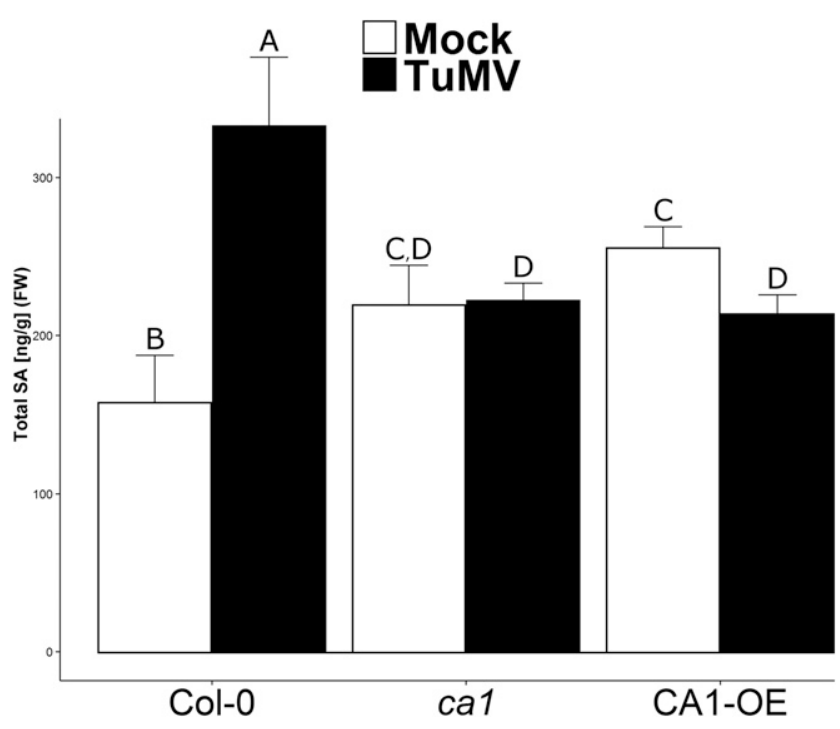

Fig. 6. Total salicylic acid (SA) accumulation in wild-type, Arabidopsis thaliana carbonic anhydrase (AtCA1) knockout, and overexpression lines challenged with Turnip mosaic virus (TuMV). Seedlings of wild-type (Col0), AtCA1 knockout (cal), and overexpression (CA1-OE) lines of Arabidopsis thaliana were inoculated with TuMV, and a mock treatment with inoculation buffer was used as control. Two days postinoculation, total (free and sugar-conjugate) SA was extracted and subjected to high-performance liquid chromatography-mass spectrometry analysis to estimate the amount of SA measured in nanograms per gram of the fresh weight $(\mathrm{FW})$. All values are the means ( \pm standard deviation) of three pools of two plants taken from three separate experiments. Different letters above each sample represent statistical significance at $P<0.001$, as assessed by student's $t$ test. 


\section{- - Mock - TuMV \\ - Col-0 $\triangle$ ca1 $\square$ CA1-OE}
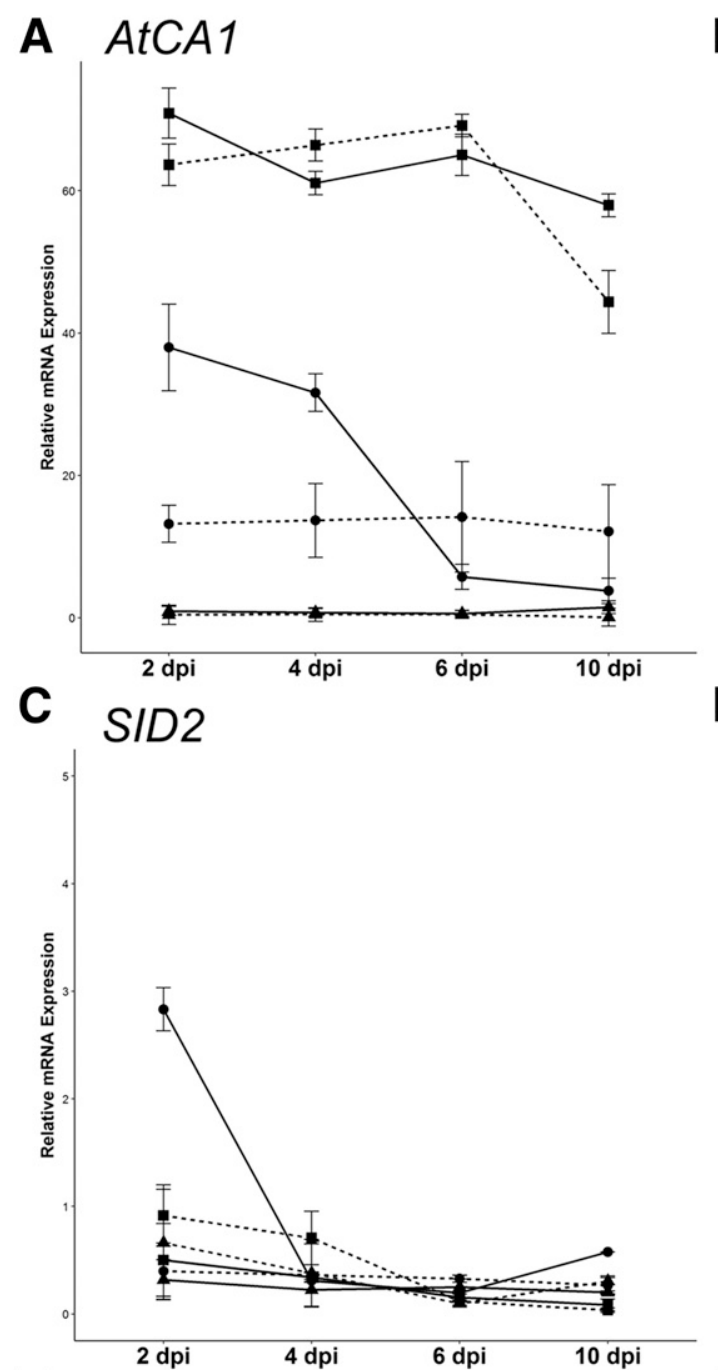

B $C P$
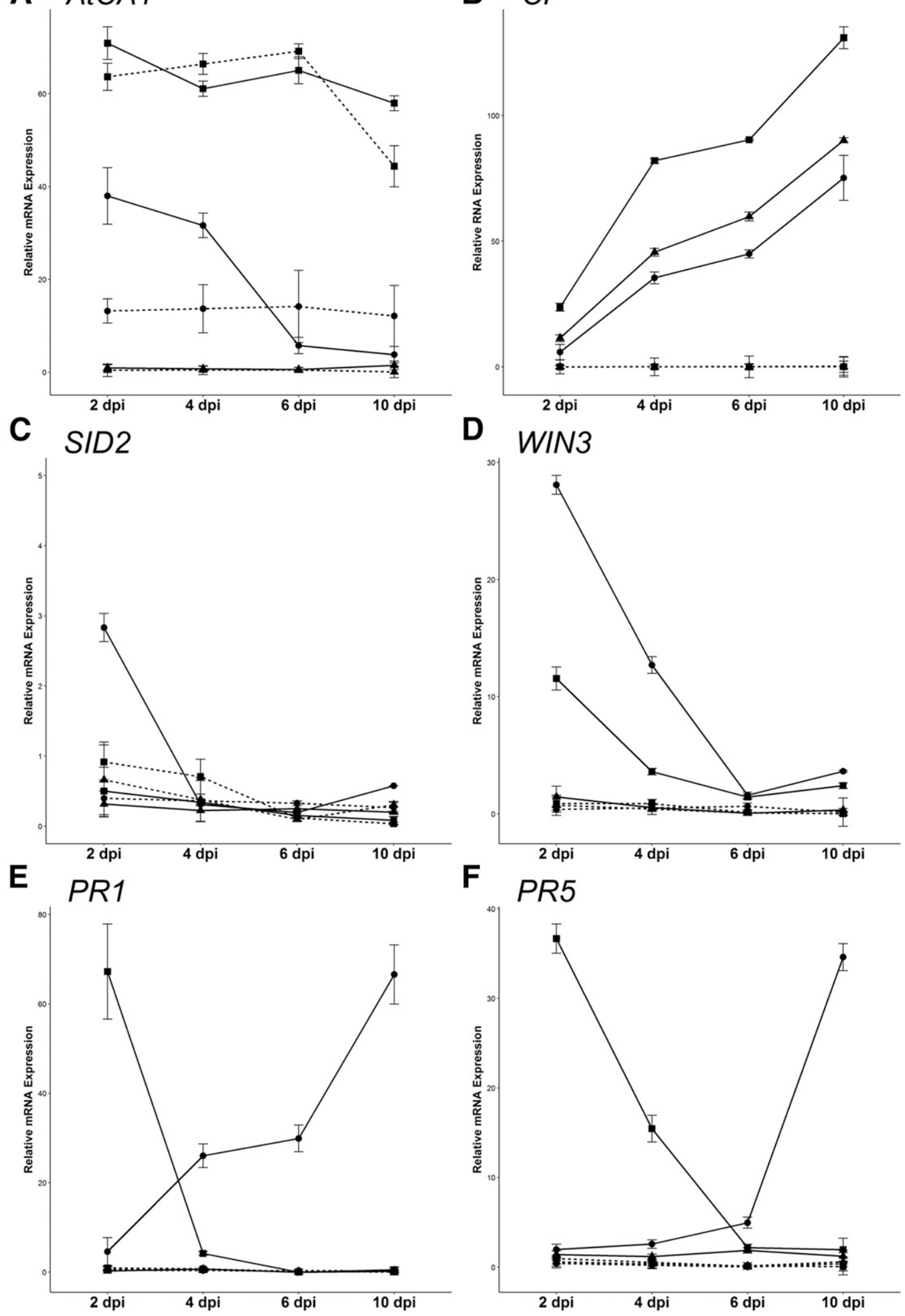

Fig. 7. Time course of the relative expression levels of hallmark genes of the salicylic acid (SA) pathway in wild-type, Arabidopsis thaliana carbonic anhydrase (AtCA1) knockout, and overexpression lines. Wild-type (Col-0), AtCA1 knockout (cal), and overexpression (CA1-OE) seedlings of Arabidopsis thaliana were inoculated with Turnip mosaic virus (TuMV), and a mock treatment with inoculation buffer was performed as control. After 2, 4, 6, and 10 days, total RNA was extracted and quantitative reverse transcription-polymerase chain reaction was performed. Relative expression levels of each gene were evaluated using A. thaliana Actin-8 for normalization. A, Transcript accumulation of AtCA1. B, RNA accumulation of TuMV coat protein (CP) showing a control of infection $\mathbf{C}$ and D, Transcript accumulation of the two positive regulators of the SA pathway, SID2 and WIN3. $\mathbf{E}$ and $\mathbf{F}$, Transcript accumulation of two genes, PR1 and PR5, induced during the SA pathway. All values are the means ( \pm standard deviation) of 16 plants taken from four separate experiments. 
is essential for normal plant physiology. Numerous positive and negative feedback loops allowing stringent regulation of SA accumulation have been described (Delaney et al. 1994; Lu 2009; Shah 2003; Shah et al. 1997; Vlot et al. 2009). Therefore, the increase of susceptibility observed in the CA1-OE line may be explained by two well-accepted antagonistic effects readjusting SA accumulation. First, inside the SA pathway, optimal levels of SA activate NPR1, which controls the onset of SA-mediated defense responses. Interestingly, NPR 1 also participates to a negative feedback loop by directly downregulating SA accumulation (Clarke et al. 2000; Delaney et al. 1995; Shah et al. 1999, 2001). Thus, constitutive expression of AtCA1, illustrated by the CA1-OE mutant line, might overexpress the SA pathway, leading to the activation of a NPR1 negative-feedback loop and, thus, shutting off SA production, directly resulting in the enhancement of TuMV susceptibility. Secondly, AtCA1 involvement in lipid biosynthesis could also directly impact the modulation of other plant hormones. Several studies revealed extensive crosstalk between hormonal signaling pathways; therefore, AtCA1 overexpression might trigger the activation of jasmonic acid or abscisic acid, which has the ability to antagonize the SA pathway (Bostock 2005; Mauch-Mani and Mauch 2005; Loake and Grant 2007; Vlot et al. 2009). Besides the essential regulation of SA accumulation, AtCA1 was identified as a target for $S$-nitrosylation during the expression of disease resistance (Wang et al. 2009). This post-translational modification is crucial to restrain AtCA1 activity and thus contributes to dampened defense responses. Hence, in the CA1-OE line, we cannot exclude the possibility of a direct inactivation of AtCA1 activity by $S$-nitrosylation, leading to weakened host defense reaction. Nonetheless, our current results prevent us from ruling out any of the above possibilities and the mechanism behind this antagonistic effect still remains to be further investigated. Validation of one or more of these hypotheses should give us a better insight into the function of AtCA1 during plant defense regulation and leads us to fully understand the interplay between HCPro, SABP3, and SA-mediated defense responses.

Overall, our results showed that potyviral HCPro is able to interact and downregulate an essential regulator of the host factor SABP3 (homologue AtCA1), for reducing SA accumulation and weakening SA-mediated defense responses to facilitate virus spread and accumulation. To validate the HCPro ability to antagonize the SA pathway out of a viral infection context, we further transiently expressed HCPro alone in SApretreated $A$. thaliana. Our results further validated the involvement of HCPro in the modulation of SA-mediated defense responses and pointed at AtCA1 as an essential partner for this mechanism. To further investigate the role played by AtCA1 during potyviral infection, it is essential to define the critical domain responsible for HCPro-AtCA1 interaction. The generation of plants with a functional AtCA1 variant or mutated form losing its ability to bind HCPro would definitively confirm the essential role of the interaction but, above all, may display enhanced resistance and potentially provide a new resistance mechanism against potyviruses.

\section{MATERIALS AND METHODS}

\section{Plant material.}

Plants of C. quinoa, A. thaliana, and Nicotiana benthamiana Domin were grown in a greenhouse maintained at $25 \pm 3^{\circ} \mathrm{C}$ with a 12-h photoperiod. A. thaliana wild-type Col-0 and the $N a h G$ mutant line were provided by S.-S. Lin at National Taiwan University, Taipei, Taiwan. Seeds for the AtCA1 (At3g01500) knockout line ( $\mathrm{cal}$ ) was obtained from the ABRC as a T-DNA insertion line (Salk_106570). Genotyping of the PCR reaction was performed using primer pairs RP-SALK_106570/LPSALK 106570 and RP-SALK 106570/LBb1.3 (Table 1), and subsequent sequence analysis of the products was carried out to identify the plants carrying an insertion at At3g01500. Homozygous lines containing a single T-DNA insert in At3g01500 were subjected to two rounds of self-fertilization and progeny analyses.

For the AtCA1 overexpression line (CA1-OE), full-length cDNA of AtCA1 was cloned into the $\mathrm{pENTR/D}$ vector (Invitrogen, Carlsbad, CA, U.S.A.) and transferred to pBCo-DC-HA plant expression vector by Gateway cloning (Invitrogen). The obtained vector was transferred into Agrobacterium tumefaciens $\mathrm{C} 58 \mathrm{C} 1$ and, then, was used for floral-dip transformation (Clough and Bent 1998; Zhang et al. 2006) of the A. thaliana wild-type accession Col-0. Transgenic plants were selected on a selection medium containing the herbicide Basta. The ectopic expression of AtCA1 was confirmed by Western blot, using the monoclonal antibody against HA tag (Santa Cruz Biotechnology, Inc., Dallas).

\section{Viral source and inoculation.}

TuMV infectious clone p35STuMVcYFPHis, which was modified, by replacement of the green fluorescent protein (GFP) ORF with a YFP ORF, from the previously constructed TuMV-GFP vector p35STuMVcGFPHis (Kung et al., 2014), was mechanically applied onto Carborundum-dusted leaves of $C$. quinoa, using a $20-\mu \mathrm{l}$ aliquot containing $1 \mu \mathrm{g}$ of DNA in sterilized water. After 6 or $7 \mathrm{dpi}$, individual local lesions were isolated and mechanically transferred to $N$. benthamiana plants, and infected leaves were collected and stored at $-80^{\circ} \mathrm{C}$ for further study. TuMV-YFP inoculum was then obtained by crushing inoculated $N$. benthamiana leaves in $10 \mathrm{mM}$ phosphate buffer (1:10, wt/vol) supplemented with Carborundum. AtCA1 knockout or overexpressed A. thaliana plants were mechanically inoculated by rubbing the inoculum on four leaves of each plant,

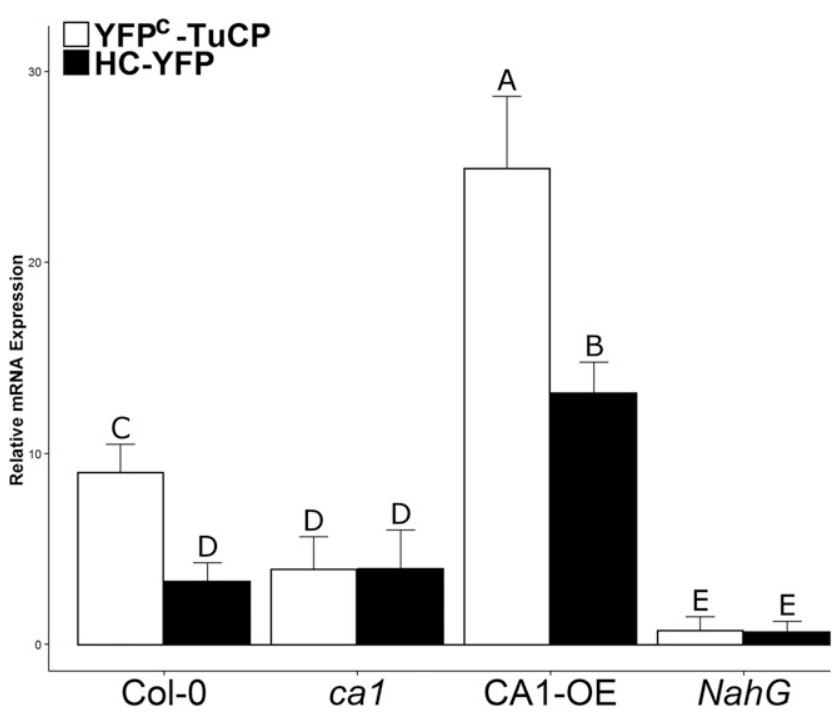

Fig. 8. Relative expression levels of PR5 in salicylic acid (SA) pretreated wild-type, Arabidopsis thaliana carbonic anhydrase (AtCA1) knockout, and overexpression lines. Turnip mosaic virus (TuMV) HCPro and coat protein (TuCP) were transiently expressed in wild-type (Col-0), AtCA1 knockout (cal), or overexpression (CA1-OE) seedlings of Arabidopsis thaliana pretreated with a 2-mM solution of SA. Two days after agroinfiltration, total RNA was extracted and quantitative reverse transcriptionpolymerase chain reaction was performed. Relative expression levels of PR5 were evaluated, using $A$. thaliana Actin- 8 for normalization. All values are the means ( \pm standard deviation) of 12 plants taken from four separate experiments. Different letters above each sample represent statistical significance at $P<0.001$, as assessed by student's $t$ test. 
using a cotton swab, and inoculum residues were rinsed out by water spray.

\section{Virus visualization.}

To determine the cell-to-cell movement and spreading of TuMV-YFP virus in inoculated leaves, YFP fluorescence was observed using fluorescence microscopy (Zeiss AXIO imager A1) at 2 dpi. Size of initial infection spots caused by the tested viruses was assessed with ImageJ software (Schneider et al. 2012).

\section{Vector construction for $\mathrm{Y} 2 \mathrm{H}$ analysis, Co-IP, colocalization, and BiFC assay.}

(ZHC, TuHC, and TuCP genes were amplified by RT-PCR from ZYMV- and TuMV-infected $N$. benthamiana plants, using primers sets $\mathrm{P}-\mathrm{ZHC} / \mathrm{N}-\mathrm{ZHC}, \mathrm{P}-\mathrm{TuHC} / \mathrm{N}-\mathrm{TuHC}$, and $\mathrm{P}-$ TuCP/N-TuCP (Table 1), respectively. The ZYMV HC-Pro ORF was amplified by PCR with the forward primer P-ZHCPro $\mathrm{NcoI}$ and reverse primer N-ZHCPro BamHI (Table 1) from the ZYMV infectious clone (Lin et al., 2007). The amplified fragment was cloned in pGBKT7 vector (Clontech, Palo Alto, CA, U.S.A.) to generate pGBKT7/ZHC-Pro as a bait. The $C$. quinoa cDNA library was constructed by the MATCHMAKER library construction and screening kit (Clontech). Described briefly below, the $C$. quinoa mRNA was purified from noninoculated C. quinoa plants, and then, the first-strand cDNA library was synthesized with CDSIII oligo-dT and coupled dC tail by RT, then amplified by PCR with SMART III oligonucleotide and CDSIII oligo-dT primers.

The full-length cDNA clone of the A. thaliana CA1 gene (AtCA1) was constructed from 2-week-old Col-0 seedlings. Total RNA was extracted using the Plant total RNA purification kit according to manufacturer's instructions (GMbiolab Co. Ltd, Taichung, Taiwan) and RT was performed, using the

Table 1. Primers sequences for cloning, mutant screening, and reverse transcription-quantitative polymerase chain reaction (qPCR)

\begin{tabular}{ll}
\hline Name & \multicolumn{1}{c}{ Sequence $\left(\mathbf{5}^{\prime}\right.$ to $\left.\mathbf{3}^{\prime}\right)$} \\
\hline Mutant line screen & \\
RP-SALK_106570 & ATCGGGTAAGGCTTCAAAGAG \\
LP-SALK_106570 & CTTCGTGGTCCGTAACATAGC \\
LBb1.3 & ATTTTGCCGATTTCGGAAC \\
Protein-protein interaction & ATCCATGGTCATCCATGGAAGTTCAGTT \\
P-ZHCPro NcoI & CCGGATCCGCCAACTCTGTAATGCTTC \\
N-ZHCPro BamHI & CACCATGTCATCCATGGAAGTTCAGTTCTTC \\
P-ZHC & GCCAACTCTGTAATGCTTCATC \\
N-ZHC & CACCATGAGTGCAGCAGGAGCCAAC \\
P-TuHC & TCCGACACGGTAGTGTTT \\
N-TuHC & CACCGCAGGTGAGACGC \\
P-TuCP & TAACCCCTTAACGCCAAGTAAG \\
N-TuCP & CACCATGTCGACCGCTCCTCTCTC \\
P-CA1 & CAGCTTCCAATGTAGTATGG \\
N-CA1 & TTTTTTTTTTTTTTTTT \\
poly-dT & \\
Gene expression & \\
qPCR_CA1-All_F & CCTTCGTGGTCCGTAACATAG \\
qPCR_CA1-All_R & TAAGGTGTAAGACCGCGTATTC \\
qPCR_TuHC_F & AGGAATTCTCACAGGCCACG \\
qPCR_TuHC_R & GGTGGTGTTTGGTTGGCATC \\
qPCR_SID2_F & ATGAGATTCAGCCTCGCTGT \\
qPCR_SID2_R & TGATGGATCTCCAATCGTCA \\
qPCR_WIN3_F & ACACCAGCCCTGATGAAGTC \\
qPCR_WIN3-R & CCCAAGTCTGTGACCCAGTT \\
qPCR_PR1_F & TTCTTCCCTCGAAAGCTCAA \\
qPCR_PR1_R & AAGGCCCACCAGAGTGTATG \\
qPCR_PR5_F & CGTACAGGCTGCAACTTTGA \\
qPCR_PR5_R & GCGTTGAGGTCAGAGACACA \\
Actin8_F & CCCAAAAGCCAACAGAGAGA \\
Actin8_R & CATCACCAGAGTCCAACACAAT \\
\hline &
\end{tabular}

SuperScript III first-strand synthesis system (Invitrogen), with polydT primers (Table 1). Subsequent PCR was performed using Ex Taq polymerase (Clontech) with the P-CA1/N-CA1 primer pair (Table 1). Full-length GUS cDNA was amplified with specific primers. Individually amplified fragments were

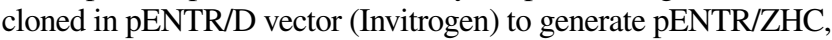
pENTR/TuHC, $p$ ENTR/TuCP, pENTR/AtCA1, and pENTR/GUS. Then, with LR Clonase enzyme (Invitrogen), ZHC, TuHC, GUS, and AtCA1 fragments were transferred into bacterial expression vectors (pMAL-DC-HA or pMAL-DC-myc) for the generation of pMAL-ZHC-myc, pMAL-TuHC-myc, pMAL-GUS-myc, and pMAL-AtCA1-HA, respectively. The same strategy was employed to transfer $\mathrm{ZHC}$, TuHC, and AtCA1 fragments into plant expression vectors to express either the yellow or cyan florescence proteins (pBCo-DC-YFP or pBCo-DC-CFP, respectively) (provided by S.-S. Lin) for the generation of pBCo-ZHC-YFP, pBCo-TuHC-YFP, and pBCo-AtCA1-CFP. And, finally, the same strategy was employed to clone TuHC, AtCA1, and $\mathrm{TuCP}$ fragments into $\mathrm{BiFC}$ vectors expressing either the $\mathrm{N}$-terminal part (pBA-NE-DC-myc) or C-terminal part (pBA-CE-DC-HA) (provided by S.-S. Lin) of the YFP, to generate pBA-NE-TuHC-myc, pBA-CE-TuHC-HA, pBA-NEAtCA1-myc, and pBA-CE-TuCP-HA.

$Y 2 H$ analysis. The pGBKT7/ZHC-Pro, pGADT7-Rec vector, and PCR products were cotransformed into Saccharomyces cerevisiae AH109 cells (Clontech). Transformants were grown at $30^{\circ} \mathrm{C}$ for 2 days on the synthetic defined (SD) medium lacking Leu and Trp, then, individual colonies were picked from plate to liquid SD medium lacking Leu and Trp and were cultured at $30^{\circ} \mathrm{C}$ overnight. Then, liquid yeast culture was transferred to the SD medium lacking His, Leu, and Trp agar plate. The plasmid of individual colonies was extracted and sequenced. The $C$. quinoa SABP3 gene (CqSABP3) amino acid sequence is shown in Figure 1B.

In vitro Co-IP of AtCAI with both ZYMV and TuHC. Escherichia coli BL21 cells were transformed with the individual plasmids expressing ZHC-myc, TuHC-myc, GUS-myc, and AtCA1-HA (pMAL-ZHC-myc, pMAL-TuHC-myc, pMAL-GUS-myc, and pMAL-AtCA1-HA, respectively). Following induced expression of recombinant proteins, $E$. coli cells were pelleted and resuspended in $1 \mathrm{ml}$ of extraction buffer $(50 \mathrm{mM}$ Tris- $\mathrm{HCl}, 150 \mathrm{mM}$ $\mathrm{NaCl}, 0.5 \%$ Triton $\mathrm{X}-100,5 \%$ glycerol, $1 \mathrm{mM}$ EDTA, and $0.02 \%$ $\mathrm{NaN}_{3}$ ) containing protease inhibitor cocktail (Roche Diagnostics, Indianapolis, IN, U.S.A.), were lysed with a sonicator 250-450 Sonifier Analog Cell Disruptor (Branson, CT, U.S.A.), and were then centrifuged at $12,000 \times g$ for $5 \mathrm{~min}$. Crude extract was loaded on amylose column (New England Biolabs, Ipswich, MA, U.S. A.) and was washed 12 times with column buffer (CB) (20 mM Tris- $\mathrm{HCl}, 200 \mathrm{mM} \mathrm{NaCl}, 1 \mathrm{mM}$ EDTA, $\mathrm{pH}$ 7.4), and then, the recombinant proteins were eluted with $1 \mathrm{ml}$ of $\mathrm{CB}$ containing $10 \mathrm{mM}$ maltose, three times. Aliquots of the purified sample containing AtCA1-HA was mixed, in equal volume, with each purified sample containing ZHC-myc, TuHC-myc, or GUSmyc (i.e., AtCA1-HA + ZHC-myc; AtCA1-HA + TuHC-myc; AtCA1-HA + GUS-myc) and was incubated at $4^{\circ} \mathrm{C}$ for $1 \mathrm{~h}$. MAb against myc-tag (Santa Cruz Biotechnology, Inc.) was added to each reaction mixture, before incubation at $4^{\circ} \mathrm{C}$ for $1 \mathrm{~h}$. Then, $25 \mu \mathrm{l}$ Mag Protein A sepharose (GE Healthcare Life Sciences, Uppsala, Sweden) was added and the mixture was incubated further for $1 \mathrm{~h}$. The tubes were kept on a magnetic platform (MagRack6) to capture the Mag Protein A sepharose beads. After washing with $600 \mu \mathrm{l}$ of extraction buffer four times, the beads were resuspended in $100 \mu \mathrm{l}$ of sample buffer and the immunoprecipitated proteins were analyzed by Western blotting, using PAb against HA-tag (Santa Cruz Biotechnology, Inc.) to detect the nontagged protein pulled down by myc MAb through Co-IP with the myc-tagged proteins. 


\section{Colocalization and $\mathrm{BiFC}$ experiment analyzed} by transient expression.

Agrobacterium tumefaciens $\mathrm{C} 58 \mathrm{C} 1$ was separately transformed with pBCo-ZHC-YFP, pBCo-TuHC-YFP, or pBCoAtCA1-CFP vector to observe the subcellular localization and colocalization of ZHC, TuHC, and their target candidate AtCA1. While Agrobacterium strain carrying pBA-NE-TuHC-myc, pBA-CE-TuHC-HA, pBA-NE-AtCA1-myc, or pBA-CE-TuCP$\mathrm{HA}$ were used to validate the direct in vivo interaction between TuMV HcPro and AtCA1 by BiFC, intact leaves of 6- to 8-weekold $N$. benthamiana plants were infiltrated with agrobacterium for transient expression. The agroinfiltation method was modified from our previous studies (Cheng et al. 2013a; Huang et al. 2015; Kung et al. 2015). In both experiments, the overnight agrobacterium cell cultures were resuspended in agroinfiltration buffer $(10 \mathrm{mM} \mathrm{MgCl} 2,150 \mu \mathrm{M}$ acetosyringone, $10 \mathrm{mM} \mathrm{MES})$. Obtained agrobacterium suspensions were adjusted to a final optical density at $600 \mathrm{~nm}\left(\mathrm{OD}_{600}\right)$ of 1.0 , were kept for $3 \mathrm{~h}$ at room temperature, and then, were directly injected into the intercellular spaces of leaves, using a needleless plastic syringe. For coinfiltrations, the agrobacterium cultures were mixed together in equal amounts. After infiltration, the plants were maintained for 2 to 3 days under controlled conditions in greenhouse facilities $\left(25 \pm 3^{\circ} \mathrm{C}\right.$ with a 12 -h photoperiod).

For colocalization, an individually infiltrated portion was taken at 2 days post-agroinfiltration (dpa) for observation by confocal microscopy. The Fluoview FV1000 confocal laser scanning microscope (Olympus, Tokyo) was used to examine the subcellular localization of YFP, CFP, and chlorophyll fluorescence. For the imaging of chlorophyll autofluorescence, excitation with a 488-nm argon laser was used and fluorescence was detected at 630 to $690 \mathrm{~nm}$. The excitation wavelength for CFP was $405 \mathrm{~nm}$ and its emission was recorded at 440 to $485 \mathrm{~nm}$. For visualization of YFP, excitation at $514 \mathrm{~nm}$ was used along with an emission window set at 520 to $550 \mathrm{~nm}$. For the CFP and YFP colocalization experiments, simultaneous imaging was conducted, using the line-sequential multitrack scanning mode of the microscope to exclude the possibility of crosstalk between the fluorophores. For BiFC analysis, infiltrated tissues were examined by fluorescent microscopy (Zeiss AXIO imager A1, Oberkochen, Germany) with YFP filter (Chroma, Bellows Falls, VT, U.S.A.).

\section{Arabidopsis thaliana agroinfiltration.}

A. thaliana wild type (Col-0), knockout (cal), and overexpression (CA1-OE) lines were infiltrated with Agrobacterium tumefaciens $\mathrm{C} 58 \mathrm{C} 1$ harboring either $\mathrm{pBCo}-\mathrm{TuHC}-\mathrm{YFP}$ or $\mathrm{pBA}-$ CE-TuCP-HA. According to Lee and Yang (2006), the overnight agrobacterium cell cultures were pelleted and resuspended in induction medium (per liter, $10.5 \mathrm{~g}$ of $\mathrm{K}_{2} \mathrm{HPO}_{4}, 4.5 \mathrm{~g}$ of $\mathrm{KH}_{2} \mathrm{PO}_{4}, 1 \mathrm{~g}$ of $\left(\mathrm{NH}_{4}\right) \mathrm{SO}_{4}, 0.5 \mathrm{~g}$ of NaCitrate, $1 \mathrm{~g}$ of glucose, $1 \mathrm{~g}$ of fructose, and $4 \mathrm{~g}$ of glycerol and $1 \mathrm{mM} \mathrm{MgSO}_{4}$ and $10 \mathrm{mM}$ MES, adjusted to $\mathrm{pH}$ 5.6) supplemented with $100 \mu \mathrm{M}$ acetosyringone and cultured for $6 \mathrm{~h}$. Cells were then pelleted and resuspended to an $\mathrm{OD}_{600}$ of 0.4 in infiltration medium $(10 \mathrm{mM}$ $\mathrm{MgSO}_{4}, 10 \mathrm{mM}$ MES; adjusted to $\mathrm{pH}$ 5.6). Attached leaves of 4week-old $A$. thaliana plants were infiltrated using a needleless plastic syringe. Two days postinfiltration, qRT-PCR and Western blotting analysis were conducted.

\section{CA1 antiserum preparation.}

The full-length cDNA of AtCA1 was cloned into bacterial protein expression vector pET32a (Novagen, Madison, WI, U.S.A.), and was then introduced into E. coli BL21 (NEB, Beverly, MA, U.S.A.) to express AtCA1 protein. Bacteriaexpressed AtCA1with six histidine residues at its $\mathrm{N}$-terminus was purified by $\mathrm{Ni}^{2+}$-NTA affinity column. The polyclonal antibody of AtCA1 (anti-CA1) was prepared from a rabbit immunized with four times weekly injections with the purified AtCA1 protein (1 mg/injection/week). At two weeks after the last injection, the antiserum was collected and used for this study.

Purified AtCA1 protein was resolved in a $12 \%$ sodium dodecyl sulphate (SDS)-polyacrylamide gel, was transferred to polyscreen polyvinylidene diflouride (PVDF) membrane (PerkinElmer, Waltham, MA, U.S.A.), and was revealed using Coomassie brillant blue R250, and the AtCA1 concentration was compared with bovine serum albumin standard protein. (Supplementary Fig. S2). Anti-CA1 polyclonal antiserum was tested by Western blot analysis as described below. After transfer, polyscreen PVDF membranes (PerkinElmer) were saturated with 7\% milk in phosphate buffered saline (PBS)-Tween and were incubated $1 \mathrm{~h}$ with anti-CA1 antibodies diluted to one-five thousandth in 5\% milk in PBS-Tween. After three PBS-Tween washes, membranes were soaked $1 \mathrm{~h}$ with antirabbit horseradish peroxidase-conjugated secondary antibody (Jackson Immunoresearch, West Grove, PA, U.S.A.) diluted to one-five thousandth, and were revealed by chemiluminescence using a MultiGel-21 system (Top Bio Co., New Taipei City, Taiwan).

\section{Western blotting.}

Total protein from $0.5 \mathrm{~g}$ of untreated or agroinfiltrated A. thaliana leaves were extracted at 2 dpa by grinding the tissues $(1: 3 \mathrm{w}: t / \mathrm{vol})$ in $3 \times$ protein sample buffer $(3 \%$ SDS, $30 \%$ glycerol, $0.01 \%$ bromophenol blue and $15 \% \beta$-mercaptoethanol). Samples were incubated at $100^{\circ} \mathrm{c}$ for $5 \mathrm{~min}$ and then the supernatant was collected after short centrifugation $(8,000 \times g$, $3 \mathrm{~min}$ ). Proteins were resolved in a $12 \%$ sodium dodecyl sulphatepolyacrylamide gel and transferred to polyscreen PVDF membrane (PerkinElmer, Waltham, MA, USA). Membranes were probed with anti-CA1 polyclonal antibodies (as describe above) and the banding signal was quantified by chemiluminescence using a MultiGel-21 system (Top Bio Co.). Then, membranes were stained with Coomassie brillant blue R250 and the amount of the large subunit of RuBisCO was used as loading control. Banding signal was quantified by Kodak Image system 4000MM (Eastman Kodak Co., Rochester, NY, U.S.A.).

\section{Real time qRT-PCR experiments.}

For gene expression experiments, leaf samples from agroinfiltrated or TuMV-infected A. thaliana were collected between 2 and 10 days posttreatment and total RNA was extracted using the Plant total RNA purification kit (GMbiolab Co. Ltd.). First-strand cDNA was synthesized from total RNA, using Superscript III reverse transcriptase (Invitrogen) with a poly_dT primer (Table 1). Real time qPCR was performed on a Rotor Gene Q system (Qiagen, Hilden, Germany) by using HOT FIREpol EvaGreen qPCR Mix Plus (Solis BioDyne, Tartu, Estonia) and one-tenth of the newly synthesized cDNAs. Transcript accumulation of AtCA1, TuMV HCPro, SID2, WIN3, PR1, and PR5 were amplified and detected, using their specific primer pairs (Table 1). PCR was performed using the following cycling conditions: $95^{\circ} \mathrm{C}$ for $15 \mathrm{~min}$ and 40 cycles of $95^{\circ} \mathrm{C}$ for $20 \mathrm{~s}, 60^{\circ} \mathrm{C}$ for $20 \mathrm{~s}$, and $72^{\circ} \mathrm{C}$ for $20 \mathrm{~s}$, followed by a melting curve ramp from $72^{\circ} \mathrm{C}$ to $95^{\circ} \mathrm{C}$ for $10 \mathrm{~s}$. All qRT-PCR experiments were conducted on three to four biological replicates for each sample and were repeated four times. For comparison of the data among experimental samples, the real-time PCR results were normalized using the levels of the housekeeping gene Actin8 amplified with Actin8_F/Actin8_R primer pair (Table 1).

\section{HPLC-MS experiments.}

To quantify total SA accumulation in A. thaliana wild-type (Col-0), knockout (cal), and overexpression (CA1-OE) lines 
during TuMV infection, leaf tissues were harvested 2 dpi and were weighed and ground in liquid nitrogen $\left(\mathrm{N}_{2}\right)$. SA extraction was performed as follows: $600 \mu \mathrm{l}$ of methanol $(90 \%)$ was added to the ground tissues and vortexed, $1 \mu \mathrm{g}$ of SA diluted in water was added to each sample as recovery control, and the resulting mixture was sonicated for $20 \mathrm{~min}$. After centrifugation at $7,500 \times g$ for $10 \mathrm{~min}$, the supernatant was collected and the pellet was re-extracted with $500 \mu$ of methanol $(100 \%)$ and recentrifuged at 7,500 $\times g$ for another $10 \mathrm{~min}$. The supernatants from both extractions were combined and were air dried using a SpeedVac system (Thermo Fisher Scientific, Waltham, MA, U.S.A.). The dried extract was resuspended in $50 \mu \mathrm{l}$ of methanol $(100 \%)$, was vortexed, was sonicated for $5 \mathrm{~min}$, and was spun through a $0.22-\mu \mathrm{m}$ nylon filter. To measure the amount of extracted SA, the samples were separated by HPLC through a COSMOSIL C18-AR-II column (Nacalai USA, San Diego, CA, U.S.A.), with a particle size of $5 \mu \mathrm{m}$ and a pore size of $12 \mathrm{~nm}$ at a mobile phase flow rate of $0.5 \mathrm{ml} / \mathrm{min}$ with a linear gradient from $95 \%$ acetic acid (5\%) and 5\% methanol to $30 \%$ acetic acid (5\%) and 70\% methanol in $35 \mathrm{~min}$, followed by an additional 15-min linear gradient to $90 \%$ acetic acid (5\%) and $10 \%$ methanol. Mass detection was performed on an amaZon speed ion trap system (Bruker, Billerica, MA, U.S.A.). Standard curve made from serial dilution of pure SA in methanol (100\%) allowed us to estimate the total SA amount in each sample.

\section{SA treatments.}

SA treatment was performed according to Naylor et al. (1998). SA ( $\mathrm{pH} 6.5$, neutralized with $\mathrm{KOH}$ ) of $1 \mathrm{mM}$ concentration was sprayed on the top leaves of plants 4 days prior to TuMV inoculation or agroinfiltration.

\section{ACKNOWLEDGEMENTS}

This work was supported by grants provided by the Ministry of Education, Taiwan, R.O.C. under the ATU plan and NCHUUCD Plant and Food Biotechnology Center, National Chung Hsing University (MOST 103-2313-B-005 -023 -MY3, MOST 104-2313-B-005-024-MY3). S. Poque conceived and designed the experiments with the contribution of S. D. Yeh, C. H. Huang, H. W. Cheng, and C. S. Lai. Experiments were performed by $\mathrm{S}$. Poque. We are grateful to $\mathrm{H}$. W. Wu for the preliminary work and to S.-S. Lin for kindly providing the A. thaliana Col-0 and $N a h G$ mutant lines. Also, we are grateful to M. H. Lee for providing real time PCR equipment to conduct qRT-PCR experiments and to D. Wang and C. S. Lai for helping us to design the SA quantification experiment and allowing us to use their HPLC-MS facilities. S. Poque wrote the paper with proofreading from S. D. Yeh. All authors read and approved the final version of the manuscript.

\section{LITERATURE CITED}

Abdelkefi, H., Sugliani, M., Ke, H., Harchouni, S., Soubigou-Taconnat, L., Citerne, S., Mouille, G., Fakhfakh, H., Robaglia, C., and Field, B. 2017. Guanosine tetraphosphate modulates salicylic acid signalling and the resistance of Arabidopsis thaliana to Turnip mosaic virus. Mol. Plant Pathol. Published online. doi:10.1111/mpp.12548

Anandalakshmi, R., Pruss, G. J. J., Ge, X., Marathe, R., Mallory, A. C. C., Smith, T. H. H., and Vance, V. B. B. 1998. A viral suppressor of gene silencing in plants. Proc. Natl. Acad. Sci. U.S.A. 95:13079-13084.

Bostock, R. M. 2005. Signal crosstalk and induced resistance: Straddling the line between cost and benefit. Annu. Rev. Phytopathol. 43:545-580.

Bouché, N., Lauressergues, D., Gasciolli, V., and Vaucheret, H. 2006. An antagonistic function for Arabidopsis DCL2 in development and a new function for DCL4 in generating viral siRNAs. EMBO J. 25: 3347-3356.

Carr, J. P., Lewsey, M. G., and Palukaitis, P. 2010. Signaling in induced resistance. Pages 57-121 in: Advances in Virus Research, Natural and
Engineered Resistance to Plant Viruses, Part II. J. P. Carr and G. Loebenstein, eds. Academic Press, New York.

Carrington, J. C., Freed, D. D., and Sanders, T. C. 1989. Autocatalytic processing of the potyvirus helper component proteinase in Escherichia coli and in vitro. J. Virol. 63:4459-4463.

Chandra-Shekara, A. C., Venugopal, S. C., Barman, S. R., Kachroo, A., and Kachroo, P. 2007. Plastidial fatty acid levels regulate resistance genedependent defense signaling in Arabidopsis. Proc. Natl. Acad. Sci. U.S.A. 104:7277-7282.

Chen, Z., Silva, H., and Klessig, D. F. 1993. Active oxygen species in the induction of plant systemic acquired resistance by salicylic acid. Science 262:1883-1886.

Cheng, H. W., Chen, K. C., Raja, J. A. J., Li, J. X., and Yeh, S. D. 2013a. An efficient tag derived from the common epitope of tospoviral NSs proteins for monitoring recombinant proteins expressed in both bacterial and plant systems. J. Biotechnol. 164:510-519.

Cheng, S. F., Huang, Y. P., Chen, L. H., Hsu, Y. H., and Tsai, C. H. 2013b. Chloroplast phosphoglycerate kinase is involved in the targeting of Bamboo mosaic virus to chloroplasts in Nicotiana benthamiana plants. Plant Physiol. 163:1598-1608.

Cheng, X., and Wang, A. 2017. The potyvirus silencing suppressor protein VPg mediates degradation of SGS3 via ubiquitination and autophagy pathways. J. Virol. 91:e01478-16.

Chung, B. Y. W., Miller, W. A., Atkins, J. F., and Firth, A. E. 2008. An overlapping essential gene in the Potyviridae. Proc. Natl. Acad. Sci. 105: 5897-5902.

Clarke, J. D., Volko, S. M., Ledford, H., Ausubel, F. M., and Dong, X. 2000. Roles of salicylic acid, jasmonic acid, and ethylene in cpr-induced resistance in Arabidopsis. Plant Cell 12:2175-2190.

Clough, S. J., and Bent, A. F. 1998. Floral dip: A simplified method for Agrobacterium-mediated transformation of Arabidopsis thaliana. Plant J. Cell. Mol. Biol. 16:735-743

Delaney, T. P., Friedrich, L., and Ryals, J. a. 1995. Arabidopsis signal transduction mutant defective in chemically and biologically induced disease resistance. Proc. Natl. Acad. Sci. U.S.A. 92:6602-6606.

Delaney, T. P. P., Uknes, S., Vernooij, B., Friedrich, L., Weymann, K., Negrotto, D., Gaffney, T., Gut-Rella, M., Kessmann, H., Ward, E., and Ryals, J. 1994. A central role of salicylic acid in plant disease resistance. Science 266:1247-1250.

Dempsey, D. A., and Klessig, D. F. 2012. SOS-too many signals for systemic acquired resistance? Trends Plant Sci. 17:538-545.

Dong, J., Chen, C., and Chen, Z. 2003. Expression profiles of the Arabidopsis WRKY gene superfamily during plant defense response. Plant Mol. Biol. 51:21-37.

Durrant, W. E., and Dong, X. 2004. Systemic acquired resistance. Annu. Rev. Phytopathol. 42:185-209.

Falk, A., Feys, B. J. J., Frost, L. N. N., Jones, J. D. G. D., Daniels, M. J. J., and Parker, J. E. E. 1999. EDS1, an essential component of R genemediated disease resistance in Arabidopsis has homology to eukaryotic lipases. Proc. Natl. Acad. Sci. U.S.A. 96:3292-3297.

Feki, S., Loukili, M. J., Triki-Marrakchi, R., Karimova, G., Old, I., Ounouna, H., Nato, A., Nato, F., Guesdon, J. L., Lafaye, P., and Elgaaied, A. B. A. 2005. Interaction between tobacco ribulose-1,5-biphosphate carboxylase/oxygenase large subunit (RubisCO-LSU) and the PVY coat protein (PVY-CP). Eur. J. Plant Pathol. 112:221-234.

Fett, J. P., and Coleman, J. R. 1994. Characterization and expression of two cDNAs encoding carbonic anhydrase in Arabidopsis thaliana. Plant Physiol. 105:707-713.

Forouhar, F., Yang, Y., Kumar, D., Chen, Y., Fridman, E., Park, S. W., Chiang, Y., Acton, T. B., Montelione, G. T., Pichersky, E., Klessig, D. F., and Tong, L. 2005. Structural and biochemical studies identify tobacco SABP2 as a methyl salicylate esterase and implicate it in plant innate immunity. Proc. Natl. Acad. Sci. U.S.A. 102:1773-1778.

García, J. A., Glasa, M., Cambra, M., and Candresse, T. 2014. Plum pox virus and sharka: A model potyvirus and a major disease. Mol. Plant Pathol. 15:226-241.

Hoang, C. V. V., and Chapman, K. D. D. 2002. Biochemical and molecular inhibition of plastidial carbonic anhydrase reduces the incorporation of acetate into lipids in cotton embryos and tobacco cell suspensions and leaves. Plant Physiol. 128:1417-1427.

Huang, C. H., Hsiao, W. R., Huang, C. W., Chen, K. C., Lin, S. S., Chen, T. C., Raja, J. A. J., Wu, H. W., and Yeh, S. D. 2015. Two novel motifs of Watermelon silver mottle virus NSs protein are responsible for RNA silencing suppression and pathogenicity. PLoS One 10:e0126161.

Huh, S. U., Kim, M. J., Ham, B. K., and Paek, K. H. 2011. A zinc finger protein Tsip1 controls Cucumber mosaic virus infection by interacting with the replication complex on vacuolar membranes of the tobacco plant. New Phytol. 191:746-762. 
Ivanov, K. I., Eskelin, K., Lõhmus, A., and Mäkinen, K. 2014. Molecular and cellular mechanisms underlying potyvirus infection. J. Gen. Virol. 95:1415-1429.

Jarvis, D. E., Ho, Y. S., Lightfoot, D. J., Schmöckel, S. M., Li, B., Borm, T. J. A., Ohyanagi, H., Mineta, K., Michell, C. T., Saber, N., Kharbatia, N. M., Rupper, R. R., Sharp, A. R., Dally, N., Boughton, B. A., Woo, Y. H., Gao, G., Schijlen, E. G. W. M., Guo, X., Momin, A. A., Negrão, S., Al-Babili, S., Gehring, C., Roessner, U., Jung, C., Murphy, K., Arold, S. T., Gojobori, T., van der Linden, C. G., van Loo, E. N., Jellen, E. N., Maughan, P. J., and Tester, M. 2017. The genome of Chenopodium quinoa. Nature 542:307-312.

Ji, L. H., and Ding, S. W. 2001. The suppressor of transgene RNA silencing encoded by Cucumber mosaic virus interferes with salicylic acidmediated virus resistance. Mol. Plant-Microbe Interact. 14:715-724.

Jiménez, I., Lopez, L., Alamillo, J. M., Valli, A., Garcia, J. A., Jiménez, I., López, L., Alamillo, J. M., Valli, A., and García, J. a. 2006. Identification of a Plum pox virus $\mathrm{CI}$-interacting protein from chloroplast that has a negative effect in virus infection. Mol. Plant-Microbe Interact 19: 350-358.

Jirage, D., Tootle, T. L. L., Reuber, T. L. L., Frost, L. N. N., Feys, B. J. J., Parker, J. E. E., Ausubel, F. M. M., and Glazebrook, J. 1999. Arabidopsis thaliana PAD4 encodes a lipase-like gene that is important for salicylic acid signaling. Proc. Natl. Acad. Sci. 96:13583-13588.

Kachroo, A., Lapchyk, L., Fukushige, H., Hildebrand, D., Klessig, D., and Kachroo, P. 2003. Plastidial fatty acid signaling modulates salicylic acid- and jasmonic acid-mediated defense pathways in the Arabidopsis ssi2 mutant. Plant Cell 15:2952-2965.

Kachroo, P., Venugopal, S. C., Navarre, D. A., Lapchyk, L., and Kachroo, A. 2005. Role of salicylic acid and fatty acid desaturation pathways in ssi2-mediated signaling. Plant Physiol. 139:1717-1735.

Kasschau, K. D., and Carrington, J. C. 2001. Long-distance movement and replication maintenance functions correlate with silencing suppression activity of potyviral HC-Pro. Virology 285:71-81.

Kasschau, K. D., Xie, Z., Allen, E., Llave, C., Chapman, E. J., Krizan, K. A., and Carrington, J. C. 2003. P1/HC-Pro, a viral suppressor of RNA silencing, interferes with Arabidopsis development and miRNA function. Dev. Cell 4:205-217.

Kim, Y. J., Maizel, A., and Chen, X. 2014. Traffic into silence: Endomembranes and post-transcriptional RNA silencing. EMBO J. 33:968-980.

Kumar, D., Gustafsson, C., and Klessig, D. F. 2006. Validation of RNAi silencing specificity using synthetic genes: Salicylic acid-binding protein 2 is required for innate immunity in plants. Plant J. 45:863-868.

Kung, Y. J., Lin, P. C., Yeh, S. D., Hong, S. F., Chua, N. H., Liu, L. Y., Lin, C. P., Huang, Y. H., Wu, H. W., Chen, C. C., and Lin, S. S. 2014. Genetic analyses of the FRNK motif function of Turnip mosaic virus uncover multiple and potentially interactive pathways of cross-protection. Mol. Plant-Microbe Interact. 27:944-955.

Kung, Y. J., You, B. J., Raja, J. A. J., Chen, K. C., Huang, C. H., Bau, H. J., Yang, C. F., Huang, C. H., Chang, C. P., and Yeh, S. D. 2015. Nucleotide sequence-homology-independent breakdown of transgenic resistance by more virulent virus strains and a potential solution. Sci. Rep. 5:9804.

Lee, M. W., Lu, H., Jung, H. W., and Greenberg, J. T. 2007. A key role for the Arabidopsis WIN3 protein in disease resistance triggered by Pseudomonas syringae that secrete AvrRpt2. Mol. Plant-Microbe Interact. 20:1192-1200.

Lee, M. W., and Yang, Y. 2006. Transient expression assay by agroinfiltration of leaves. Pages 225-229 in: Methods in Molecular Biology: Methods in Molecular Biology. J. Salinas and J. Sanchez-Serrano, eds. Humana Press, New York.

Lin, L., Shi, Y., Luo, Z., Lu, Y., Zheng, H., Yan, F., Chen, J., Chen, J., Adams, M. J., and Wu, Y. 2009. Protein-protein interactions in two potyviruses using the yeast two-hybrid system. Virus Res. 142:36-40.

Lin, S. S., Wu, H. W., Jan, F. J., Hou, R. F., and Yeh, S. D. 2007. Modifications of the helper component-protease of Zucchini yellow mosaic virus for generation of attenuated mutants for cross protection against severe infection. Phytopathology 97:287-296.

Loake, G., and Grant, M. 2007. Salicylic acid in plant defence-The players and protagonists. Curr. Opin. Plant Biol. 10:466-472.

Love, A. J., Geri, C., Laird, J., Carr, C., Yun, B. W., Loake, G. J., Tada, Y., Sadanandom, A., and Milner, J. J. 2012. Cauliflower mosaic virus protein P6 inhibits signaling responses to salicylic acid and regulates innate immunity. PLoS One 7:e47535.

Love, A. J., Laird, J., Holt, J., Hamilton, A. J., Sadanandom, A., and Milner, J. J. 2007. Cauliflower mosaic virus protein P6 is a suppressor of RNA silencing. J. Gen. Virol. 88:3439-3444.

Lu, H. 2009. Dissection of salicylic acid-mediated defense signaling networks. Plant Signal. Behav. 4:713-717.

Lu, H., Rate, D. N., Song, J. T., and Greenberg, J. T. 2003. ACD6, a novel ankyrin protein, is a regulator and an effector of salicylic acid signaling in the Arabidopsis defense response. Plant Cell Online 15: 2408-2420.

Malamy, J., Carr, J. P. P., Klessig, D. F. F., and Raskin, I. 1990. Salicylic acid: A likely endogenous signal in the resistance response of tobacco to viral infection. Science 250:1002-1004.

Mauch-Mani, B., and Mauch, F. 2005. The role of abscisic acid in plantpathogen interactions. Curr. Opin. Plant Biol. 8:409-414.

Métraux, J. P., Signer, H., Ryals, J., Ward, E., Wyss-Benz, M., Gaudin, J., Raschdorf, K., Schmid, E., Blum, W., and Inverardi, B. 1990. Increase in salicylic acid at the onset of systemic acquired resistance in cucumber. Science 250:1004-1006.

Morel, J. B., Godon, C., Mourrain, P., Béclin, C., Boutet, S., Feuerbach, F., Proux, F., and Vaucheret, H. 2002. Fertile hypomorphic ARGONAUTE (ago1) mutants impaired in post-transcriptional gene silencing and virus resistance. Plant Cell Online 14:629-639.

Mou, Z., Fan, W., and Dong, X. 2003. Inducers of plant systemic acquired resistance regulate NPR1 function through redox changes. Cell 113: 935-944.

Nakahara, K. S., Masuta, C., Yamada, S., Shimura, H., Kashihara, Y., Wada, T. S., Meguro, A., Goto, K., Tadamura, K., Sueda, K., Sekiguchi, T., Shao, J., Itchoda, N., Matsumura, T., Igarashi, M., Ito, K., Carthew, R. W., and Uyeda, I. 2012. Tobacco calmodulin-like protein provides secondary defense by binding to and directing degradation of virus RNA silencing suppressors. Proc. Natl. Acad. Sci. U.S.A. 109: 10113-10118.

Nawrath, C., Heck, S., Parinthawong, N., and Métraux, J. P. 2002. EDS5, an essential component of salicylic acid-dependent signaling for disease resistance in Arabidopsis, is a member of the MATE transporter family. Plant Cell Online 14:275-286.

Naylor, M., Murphy, A. M., Berry, J. O., and Carr, J. P. 1998. Salicylic acid can induce resistance to plant virus movement. Mol. Plant-Microbe Interact. 11:860-868

Pallett, D. W., Thurston, M. I., Cortina-Borja, M., Edwards, M. L., Alexander, M., Mitchell, E., Raybould, A. F., and Cooper, J. I. 2002. The incidence of viruses in wild Brassica rapa ssp. sylvestris in southern England. Ann. Appl. Biol. 141:163-170.

Palma, K., Zhang, Y., and Li, X. 2005. An importin alpha homolog, MOS6, plays an important role in plant innate immunity. Curr. Biol. 15:1129-1135.

Park, S. W., Kaimoyo, E., Kumar, D., Mosher, S., and Klessig, D. F. 2007. Methyl salicylate is a critical mobile signal for plant systemic acquired resistance. Science 318:113-116.

Pieterse, C. M. J., and Van Loon, L. C. 2004. NPR1: The spider in the web of induced resistance signaling pathways. Curr. Opin. Plant Biol. 7: 456-464.

Plisson, C., Drucker, M., Blanc, S., German-Retana, S., Le Gall, O., Thomas, D., and Bron, P. 2003. Structural characterization of HC-Pro, a plant virus multifunctional protein. J. Biol. Chem. 278:23753-23761.

Restrepo, S., Myers, K. L., del Pozo, O., Martin, G. B., Hart, A. L., Buell, C. R., Fry, W. E., and Smart, C. D. 2005. Gene profiling of a compatible interaction between Phytophthora infestans and Solanum tuberosum suggests a role for carbonic anhydrase. Mol. Plant-Microbe Interact. 18: 913-922.

Revers, F., and García, J. A. 2015. Chapter three - Molecular biology of potyviruses. Adv. Virus Res. 92:101-199.

Riechmann, J. L., Lain, S., and Garcia, J. A. 1992. Highlights and prospects of potyvirus molecular biology. J. Gen. Virol. 73:1-16.

Rietz, S., Stamm, A., Malonek, S., Wagner, S., Becker, D., MedinaEscobar, N., Corina Vlot, A., Feys, B. J., Niefind, K., and Parker, J. E. 2011. Different roles of enhanced disease susceptibility1 (EDS1) bound to and dissociated from phytoalexin deficient4 (PAD4) in Arabidopsis immunity. New Phytol. 191:107-119.

Rivas-San Vicente, M., and Plasencia, J. 2011. Salicylic acid beyond defence: Its role in plant growth and development. J. Exp. Bot. 62: 3321-3338

Ruiz, M., Voinnet, O., Baulcombe, D. C. D., Ruiz, T. M., Voinnet, O., and Baulcombe, D. C. D. 1998. Initiation and maintenance of virus-induced gene silencing. Plant Cell Online 10:937-946.

Schneider, C. A., Rasband, W. S., and Eliceiri, K. W. 2012. NIH Image to ImageJ: 25 years of image analysis. Nat. Methods 9:671-675.

Serino, L., Reimmann, C., Baur, H., Beyeler, M., Visca, P., and Haas, D. 1995. Structural genes for salicylate biosynthesis from chorismate in Pseudomonas aeruginosa. Mol. Gen. Genet. 249:217-228.

Shah, J. 2003. The salicylic acid loop in plant defense. Curr. Opin. Plant Biol. 6:365-371.

Shah, J., Kachroo, P., and Klessig, D. F. 1999. The Arabidopsis ssil mutation restores pathogenesis-related gene expression in nprl plants and renders defensin gene expression salicylic acid dependent. Plant Cell Online 11:191-206. 
Shah, J., Kachroo, P., Nandi, A., and Klessig, D. F. 2001. A recessive mutation in the Arabidopsis SSI2 gene confers SA- and NPRI-independent expression of $P R$ genes and resistance against bacterial and oomycete pathogens. Plant J. 25:563-574.

Shah, J., Tsui, F., and Klessig, D. F. 1997. Characterization of a salicylic acid-insensitive mutant (sail) of Arabidopsis thaliana, identified in a selective screen utilizing the SA-inducible expression of the tms 2 gene. Mol. Plant-Microbe Interact. 10:69-78.

Shah, J., and Zeier, J. 2013. Long-distance communication and signal amplification in systemic acquired resistance. Front. Plant Sci. 4:1-16.

Simón-Mateo, C., Garcia, J. A., Simón-Mateo, C., and García, J. A. 2011. Antiviral strategies in plants based on RNA silencing. Biochim. Biophys. Acta. Gene Regul. Mech. 1809:722-731.

Slaymaker, D. H., Navarre, D. A., Clark, D., del Pozo, O., Martin, G. B., and Klessig, D. F. 2002. The tobacco salicylic acid-binding protein 3 (SABP3) is the chloroplast carbonic anhydrase, which exhibits antioxidant activity and plays a role in the hypersensitive defense response. Proc. Natl. Acad. Sci. U.S.A. 99:11640-11645.

Song, J. T., Lu, H., McDowell, J. M., and Greenberg, J. T. 2004. A key role for $A L D 1$ in activation of local and systemic defenses in Arabidopsis. Plant J. 40:200-212.

Thurston, M., Pallett, D., Cortina-Borja, M., Edwards, M., Raybould, A., and Cooper, J. 2001. The incidence of viruses in wild Brassica nigra in Dorset (UK). Ann. Appl. Biol. 139:277-284.

del Toro, F. J., Donaire, L., Aguilar, E., Chung, B.-N., Tenllado, F., and Canto, T. 2017. Potato virus $Y$ HCPro suppression of antiviral silencing in Nicotiana benthamiana plants correlates with its ability to bind in vivo to 21- and 22nucleotide small RNAs of viral sequence. J. Virol. 91:e00367-17.

Urcuqui-Inchima, S., Walter, J., Drugeon, G., German-Retana, S., Haenni, A. L., Candresse, T., Bernardi, F., and Le Gall, O. 1999. Potyvirus helper component-proteinase self-interaction in the yeast two-hybrid system and delineation of the interaction domain involved. Virology 258:95-99.

Vernooij, B., Uknes, S., Ward, E., and Ryals, J. 1994. Salicylic acid as a signal molecule in plant-pathogen interactions. Curr. Opin. Cell Biol. 6: 275-279.

Vlot, A. C., Dempsey, D. A., and Klessig, D. F. 2009. Salicylic acid, a multifaceted hormone to combat disease. Annu. Rev. Phytopathol. 47: 177-206.

Vlot, A. C., Klessig, D. F., and Park, S. W. 2008. Systemic acquired resistance: The elusive signal(s). Curr. Opin. Plant Biol. 11:436-442.

Voinnet, O. 2001. RNA silencing as a plant immune system against viruses. Trends Genet. 17:449-459.

Wang, X. B., Jovel, J., Udomporn, P., Wang, Y., Wu, Q., Li, W. X., Gasciolli, V., Vaucheret, H., and Ding, S. W. 2011. The 21-nucleotide, but not 22-nucleotide, viral secondary small interfering RNAs direct potent antiviral defense by two cooperative argonautes in Arabidopsis thaliana. Plant Cell Online 23.

Wang, Y. Q., Feechan, A., Yun, B. W., Shafiei, R., Hofmann, A., Taylor, P., Xue, P., Yang, F. Q., Xie, Z. S., Pallas, J. A., Chu, C. C., and Loake, G. J.
2009. S-nitrosylation of AtSABP3 antagonizes the expression of plant immunity. J. Biol. Chem. 284:2131-2137.

Weber, H. 2002. Fatty acid-derived signals in plants. Trends Plant Sci. 7:217-224.

White, K. A. 2015. The polymerase slips and PIPO exists. EMBO Rep. 16:885-886.

White, R. F. 1979. Acetylsalicylic acid (aspirin) induces resistance to tobacco mosaic virus in tobacco. Virology 99:410-412.

Wiermer, M., Feys, B. J., and Parker, J. E. 2005. Plant immunity: The EDS1 regulatory node. Curr. Opin. Plant Biol. 8:383-389.

Wildermuth, M. C. C., Dewdney, J., Wu, G., and Ausubel, F. M. M. 2001. Isochorismate synthase is required to synthesize salicylic acid for plant defence. Nature 414:562-565.

Williams, T. G., Flanagan, L. B., and Coleman, J. R. 1996. Photosynthetic gas exchange and discrimination against $13 \mathrm{C} 0$, and $\mathrm{C} 18 \mathrm{O} 16 \mathrm{O}$ in tobacco plants modified by an antisense construct to have low chloroplastic carbonic anhydrase. Plant Physiol. 112:319-326.

Wu, H. W., Lin, S. S., Chen, K. C., Yeh, S. D., and Chua, N. H. 2010. Discriminating mutations of HC-Pro of Zucchini yellow mosaic virus with differential effects on small RNA pathways involved in viral pathogenicity and symptom development. Mol. Plant-Microbe Interact. 23:17-28.

Wu, Y., Zhang, D., Chu, J. Y., Boyle, P., Wang, Y., Brindle, I. D., De Luca, V., and Després, C. 2012. The Arabidopsis NPR1 protein is a receptor for the plant defense hormone salicylic acid. Cell Reports 1:639-647.

Yaeno, T., Matsuda, O., and Iba, K. 2004. Role of chloroplast trienoic fatty acids in plaint disease defense responses. Plant J. 40:931-941.

Yalpani, N., Silverman, P., Wilson, T. M., Kleier, D. A., and Raskin, I. 1991. Salicylic acid is a systemic signal and an inducer of pathogenesis-related proteins in virus-infected tobacco. Plant Cell Online 3:809-818.

Yamamoto, S., Katagiri, M., Maeno, H., and Hayaishi, O. 1965. Salicylate hydroxylase, a monooxygenase requiring flavin adenine dinucleotide I. Purification and general properties. J. Biol. Chem. 240:3408-3413.

Yang, L., Xu, Y., Liu, Y., Meng, D., Jin, T., and Zhou, X. 2016. HC-Pro viral suppressor from tobacco vein banding mosaic virus interferes with DNA methylation and activates the salicylic acid pathway. Virology 497: 244-250.

Zhang, X., Henriques, R., Lin, S. S., Niu, Q. W., and Chua, N. H. 2006. Agrobacterium-mediated transformation of Arabidopsis thaliana using the floral dip method. Nat. Protoc. 1:641-646.

Zhao, J., Zhang, X., Hong, Y., and Liu, Y. 2016. Chloroplast in plant-virus interaction. Front. Microbiol. 7:1565.

Zheng, H., Yan, F., Lu, Y., Sun, L., Lin, L., Cai, L., Hou, M., and Chen, J. 2011. Mapping the self-interacting domains of TuMV HC-Pro and the subcellular localization of the protein. Virus Genes 42:110-116.

Ziebell, H., Payne, T., Berry, J. O., Walsh, J. A., and Carr, J. P. 2007. A cucumber mosaic virus mutant lacking the $2 \mathrm{~b}$ counter-defence protein gene provides protection against wild-type strains. J. Gen. Virol. 88: 2862-2871. 